\title{
Tribological investigation of diamond nanoparticles for steel/steel contacts in boundary lubrication regime
}

\author{
Ankush Raina ${ }^{1}$ Ankush Anand ${ }^{1}$
}

Received: 5 June 2017/ Accepted: 21 August 2017/Published online: 30 August 2017

(C) The Author(s) 2017. This article is an open access publication

\begin{abstract}
This paper presents an investigation of nanodiamond additives (ND) in combination with copper oxide $(\mathrm{CuO})$ and hexagonal boron nitride (h-BN) particles mixed in PAO (poly-alpha-olefin) oil. The experimentation was performed for a ball on disc configuration using steel/steel contacts in the boundary lubrication regime. The loads were varied from 20 to $100 \mathrm{~N}$ and sliding velocity was kept constant at $0.58 \mathrm{~m} / \mathrm{s}$. The wear behavior was evaluated using SEM images of the worn-out disc surfaces. EDS analysis of the samples was performed to find out the chemical content of the worn surfaces. Results obtained therein demonstrated that oil containing $\mathrm{CuO} / \mathrm{ND}$ and h-BN/ND exhibited better frictional and wear characteristics. For $\mathrm{CuO} / \mathrm{ND}$ containing lubricant, the maximum decrease in friction coefficient is $15.45 \%$ in comparison to the $\mathrm{CuO}$ oil, whereas for $\mathrm{h}-\mathrm{BN} / \mathrm{ND}$ containing additives the overall decrease is $25.45 \%$. It was observed that the combined effect of $\mathrm{CuO} / \mathrm{ND}$ and h-BN/ND due to their intrinsic characteristics led to the overall improvement in lubrication properties of the base oil.
\end{abstract}

Keywords Boundary lubrication · Wear · Friction · Nanodiamond · Scuffing

Ankush Anand

anand.ankush13@gmail.com

1 Department of Mechanical Engineering, Shri Mata Vaishno Devi University, Katra, Jammu and Kashmir 182320, India

\section{Introduction}

Over the past few decades, the uses of nanoparticles as lubricant additives have remained an active area of research. The use of nanoparticles in lubricating oils has significantly improved the tribological properties one or the other way. This is certainly due to antifriction, antiwear and extreme pressure capabilities of different nanoparticles. Various studies in this context reveal that the performance of a lubricant mainly depends on the number of factors which includes: concentration, nanoparticles size, normal load, sliding velocity, surface roughness and most importantly the sliding pairs.

Alves et al. (2016) revealed that tiny particles have large potential to reduce the friction and wear particularly at low concentrations. In the same context, Reeves et al. (2013) observed that an appropriate size of nanoparticles and composite surface roughness are also important parameters for better friction and wear characteristics. Thottackkad et al. (2014) studied the effect of $\mathrm{CuO}$ nanoparticles in SAE 20W40 engine oil at different concentrations and revealed that $0.53 \mathrm{wt} \%$ is the optimum concentration for better tribological properties. Chou and Lee (2010) reported that the wear mechanism for steel/aluminum alloy contacts is entirely different from steel/steel contacts. However, in most of the cases, the improvement in tribological properties is due to the ball bearing effect (Wu et al. 2007), mending effect (Liu et al. 2004; Çelik et al. 2013), polishing effect (Nunn et al. 2015) and protective film formation capabilities (Battez et al. 2007; Alves et al. 2016) of different nanoparticles.

In the recent past, the use of nanodiamond as a lubricant additive has gained much attention of researchers due to their significant physical and chemical properties. These include their octagonal shape (almost spherical shape), 
high thermal conductivity, high hardness value and above all their environment friendliness. Literature offers us a number of studies pertaining to the use of diamond nanoparticles for steel/steel contacts under different lubricating conditions, which have been summarized in Table 1 . Most of the studies in this context reveal that low concentration is sufficient to improve the tribological properties of different oils. However, the underlying mechanisms for these improvements are somewhat different. Novak et al. (2014) and Kim et al. (2013) observed that the rolling action of diamond nanoparticles is the main reason for reduction in frictional coefficients. However, Elomaa et al. (2013) and Chou and Lee (2010) proposed that the formation of the tribolayer containing diamond nanoparticles is responsible for reduced coefficient of friction. Moreover, the use of diamond additives also prevents the metal to metal contact due to their high hardness value (Peng et al. 2009a, b). Apart from these, the heat carrying capacity of diamond nano additives enables their use as antiscuffing agents. Different investigations illustrate that the scuffing life of lubricating oils containing nanodiamonds may increase by manifold (Elomaa et al. 2013; Kim et al. 2016, Chu et al. 2010). This is essentially due to the retention of oil films even at high loads.

The use of nanodiamond in combination with other additives further enhanced the tribological properties of

Table 1 Different investigations using nanodiamond as lubricant additive

\begin{tabular}{|c|c|c|c|c|c|}
\hline $\begin{array}{l}\text { S. } \\
\text { no. }\end{array}$ & Lubricating oil & $\begin{array}{l}\text { Contact } \\
\text { type/material }\end{array}$ & $\begin{array}{l}\text { Nanoparticle } \\
\text { size }(\mathrm{nm})\end{array}$ & Concentration & Observations/results \\
\hline 1 & $\begin{array}{l}\text { Commercial marine } \\
\text { engine oils (Kim et al. } \\
\text { 2016) }\end{array}$ & $\begin{array}{l}\text { Ball on disk/steel- } \\
\text { steel }\end{array}$ & 32.6 & $\begin{array}{l}0.1,0.3,0.5 \\
\quad 1.0 \mathrm{wt} \%\end{array}$ & $\begin{array}{l}\text { Minimum wear at } 0.3 \mathrm{wt} \% \\
\text { Beyond } 0.3 \mathrm{wt} \% \text {, wear increases due to abrasive action } \\
\text { of nanoparticles } \\
\text { Scuffing life increases with increase in conc. and is } \\
\text { maximum at } 1 \mathrm{wt} \%\end{array}$ \\
\hline 2 & $\begin{array}{l}\text { Paraffin liquid (Kim et al. } \\
\text { 2013) }\end{array}$ & $\begin{array}{l}\text { Ball on disk/steel- } \\
\text { steel }\end{array}$ & $5-10$ & $0.05,0.5 \mathrm{wt} \%$ & $\begin{array}{l}\text { High hardness of nanoparticles minimizes metal to } \\
\text { metal contact } \\
\text { High heat dissipation capability enhances the scuffing } \\
\text { load capacity } \\
\text { Minimum COF with } 0.5 \mathrm{wt} \%\end{array}$ \\
\hline 3 & $\begin{array}{l}\text { Ethylene glycol (Elomaa } \\
\text { et al. 2013) }\end{array}$ & $\begin{array}{l}\text { Ball on disk/steel- } \\
\text { steel }\end{array}$ & 15 & $\begin{array}{l}0.55,1.1,2.2 \\
\quad 3.7 \mathrm{wt} \%\end{array}$ & $\begin{array}{l}\text { Wear rate minimum at } 0.55 \text { and } 2.2 \mathrm{wt} \% \\
\mathrm{COF} \text { minimum at } 1.1 \mathrm{wt} \%\end{array}$ \\
\hline 4 & $\begin{array}{l}\text { CPC R68 Commercial } \\
\text { oil (Chu et al. 2010) }\end{array}$ & $\begin{array}{l}\text { Circular block on } \\
\text { block/steel-steel }\end{array}$ & 4.37 & $1,2,3$ vol\% & $\begin{array}{l}\text { COF minimum at } 2 \text { and } 3 \mathrm{vol} \% \\
\text { Number of surface failures attributed to scuffing were } \\
\text { reduced }\end{array}$ \\
\hline 5 & $\begin{array}{l}\text { Paraffin (Peng et al. } \\
\text { 2009a, b) }\end{array}$ & $\begin{array}{l}\text { Ball on ring/steel- } \\
\text { steel }\end{array}$ & 110 & $\begin{array}{l}0.025,0.05,0.1 \\
0.2,0.5,1,2 \\
5 \text { wt } \%\end{array}$ & $\begin{array}{l}\text { Wear scar diameter minimum for } 0.2-0.5 \mathrm{wt} \% \\
\text { Load-carrying capacity maximum at } 0.2 \mathrm{wt} \% \\
\text { COF minimum at } 0.2 \mathrm{wt} \%\end{array}$ \\
\hline 6 & $\begin{array}{l}\text { Mineral oil (Marko et al. } \\
\text { 2015) }\end{array}$ & $\begin{array}{l}\text { Four ball tester/ } \\
\text { steel-steel }\end{array}$ & 55.7 & $\begin{array}{l}0.00125,0.0025 \\
0.005,0.01 \text { wt } \%\end{array}$ & $\begin{array}{l}\text { COF and wear decreases as nanoparticle conc. } \\
\text { increases and is minimum at } 0.01 \mathrm{wt} \% \\
\text { Since the study up to } 0.01 \mathrm{wt} \% \text { conc. is carried out, it } \\
\text { is difficult to predict the behavior beyond } 0.01 \mathrm{wt} \%\end{array}$ \\
\hline 7 & $\begin{array}{l}\text { Paraffin oil (Novak et al. } \\
\text { 2014) }\end{array}$ & $\begin{array}{l}\text { Ball on disk/steel- } \\
\text { steel }\end{array}$ & $3-10$ & $0.5,1.0,2.0 \mathrm{wt} \%$ & $\begin{array}{l}\text { Minimum COF at } 1.0 \mathrm{wt} \% \\
\text { Reduction in COF is higher for low sliding speeds and } \\
\text { smooth surfaces } \\
\text { Minimum wear for rough surfaces when subjected to } \\
\text { high sliding speeds }\end{array}$ \\
\hline 8 & $\begin{array}{l}\text { Commercial oil (Chou } \\
\text { and Lee 2010) }\end{array}$ & $\begin{array}{l}\text { Ball on disk/steel- } \\
\text { steel/steel-Al } \\
\text { alloy }\end{array}$ & 20 & $0.05,0.1,0.15 \mathrm{~g} / 1$ & $\begin{array}{l}\text { For carbon steel, wear is minimum at a conc. of } \\
0.05 \mathrm{~g} / \mathrm{l} \\
\text { For aluminum alloy, wear is minimum at conc. of } \\
0.1 \mathrm{~g} / 1\end{array}$ \\
\hline 9 & $\begin{array}{l}\text { Liquid Paraffin (Peng } \\
\text { et al. 2009a, b) }\end{array}$ & $\begin{array}{l}\text { Ball on ring/steel- } \\
\text { steel }\end{array}$ & $110,232,347$ & $\begin{array}{l}0.0125,0.025 \\
0.05,0.1,0.2 \\
0.5,1 \mathrm{wt} \%\end{array}$ & $\begin{array}{l}\text { Wear scar diameter and COF minimum for } 110 \\
\text { particles at a conc. of } 0.2 \mathrm{wt} \% \\
\text { Abrasive action of large-sized nanoparticles enhances } \\
\text { wear }\end{array}$ \\
\hline
\end{tabular}


different lubricants. Investigations made by Ivanov et al. (2010), Michail et al. (2009), Ivanov et al. (2012) and Shenderova et al. (2014) reveal that addition of $\mathrm{Cu}$, PTFE, Mo and MoDDP in the presence of nanodiamond resulted in excellent lubrication properties when compared with individual nanoparticles. However, the underlying mechanism for the effectiveness of these nanoparticles could not be established due to the presence of different additives in commercial oil. Subsequent investigation was performed to explore the synergy of nanodiamonds with MoDDP in the presence of PAO (poly-alpha-olefin) base oil (Nunn et al. 2015). Results obtained therein demonstrate that the polishing effect of nanodiamonds along with the film formation capability of MoDDP was the main reason for the improved frictional characteristics.

Studies exploring the synergetic effects are very encouraging and demand the use of diamond nanoparticles in the presence of other important additives. The present study is aimed to evaluate the effect of $\mathrm{CuO}$ and h-BN nanoparticles in the presence of nanodiamond. A $0.5 \mathrm{wt} \%$ of $\mathrm{CuO}$ and h-BN and $0.2 \mathrm{wt} \%$ of ND was used in the base oil. The concentration of both the nanoparticles was finalized on the basis of optimum results obtained in the previous studies (Thottackkad et al. 2014; Peng et al. 2009a, b). The experimentation was carried out using PAO base oil for ball on disc configuration. The results were obtained for steel/steel contacts in the boundary lubrication regime.

\section{Experimental details}

\section{Materials and lubricants}

The study was performed using the nanoparticles of copper oxide $(\mathrm{CuO})$, boron nitride $(\mathrm{h}-\mathrm{BN})$ and nanodiamond (ND) as received from $\mathrm{M} / \mathrm{s}$ Sigma-Aldrich. The diameter of nanoparticles was typically in the range of 60-90 nm. Experiments were performed using synthetic PAO 4 base oil, as it finds a variety of applications including in gear oils, compressor oils, engine oils, hydraulic fluids and other functional fluids. Table 2 gives the information about the different properties of the base oil. A total of six lubricants were used in the study: PAO base oil, PAO $+0.5 \% \mathrm{CuO}$,
$\mathrm{PAO}+0.2 \% \mathrm{ND}, \mathrm{PAO}+0.5 \% \mathrm{CuO}+0.2 \% \mathrm{ND}, \mathrm{PAO}$ $+0.5 \% \mathrm{~h}-\mathrm{BN}$ and PAO $+0.5 \% \mathrm{~h}-\mathrm{BN}+0.2 \%$ ND. Lubricant samples were prepared by the ultrasonication of nanoparticles in base oil for $30 \mathrm{~min}$ using probe-type sonicator (Qsonica Sonicators, USA).

The balls used in the experiments were made of AISI $52100100 \mathrm{Cr} 6$ steel having $10 \mathrm{~mm}$ diameter and hardness value of $63-66 \mathrm{HRC}$. The $R_{\mathrm{a}}$ value of the ball was $0.020 \pm 0.005 \mu \mathrm{m}$. The discs were made from EN-31 steel having $40 \mathrm{~mm}$ diameter and $8 \mathrm{~mm}$ thickness. The steel discs were first made smooth by using emery papers of different grades. Then, diamond polishing was carried out to obtain a mirror-like finish. A 3-D profilometer was used to quantify the surface roughness of the polished samples. The $R_{\text {a }}$ value of steel discs was in the range of $0.022-0.024 \mu \mathrm{m}$. Different constituent elements of both the materials used in the study are given in Table 3.

\section{Tribological tests}

Tribological studies were carried out on a unidirectional ball on disc tribometer (DUCOM), in accordance with ASTM G-99 standards. The friction force was recorded by a load cell, inbuilt in the machine, and the friction coefficient was obtained after normalizing the friction force by normal load. Experiments were performed in the boundary lubrication regime at different loads of 20,40, 60, 80 and $100 \mathrm{~N}$, corresponding to Hertzian contact stress of 0.846 , $1.061,1.220,1.343$ and $1.447 \mathrm{GPa}$, respectively. The sliding velocity was kept at $0.58 \mathrm{~m} / \mathrm{s}$ and each test was run for a sliding distance of $500 \mathrm{~m}$. The minimum lubricant film thickness was calculated using Hamrock and Dowson formula (1978) given in Eq. 1:

$h_{\min }=7.43 R\left(1-0.85 \mathrm{e}^{-0.31 k}\right)\left(\eta u / E^{*} R\right)^{0.65}\left(L / E^{*} R^{2}\right)^{-0.21}$,

where $k$ is the ellipticity parameter, $R$ the composite radius (m), $\eta$ the absolute viscosity ( $\mathrm{Pa} \mathrm{s}$ ), $u$ the sliding velocity $(\mathrm{m} / \mathrm{s}), E^{*}$ the composite elasticity modulus $(\mathrm{Pa})$ and $L$ the $\operatorname{load}(\mathrm{N})$.

The thickness of the oil film for a load of $100 \mathrm{~N}$ is $5.073 \mathrm{~nm}$, the detailed calculation for which is shown in "Appendix". Similarly, on the basis of Eq. 1, the film

Table 2 Rheological properties of base oil

\begin{tabular}{|c|c|c|c|c|c|c|c|c|}
\hline \multirow[t]{2}{*}{ Base oil } & \multirow[t]{2}{*}{ Density (g/ml. @23 C) } & \multicolumn{2}{|c|}{$\begin{array}{l}\text { Dynamic viscosity } \\
\text { (cP) }\end{array}$} & \multicolumn{2}{|c|}{$\begin{array}{l}\text { Kinematic viscosity } \\
\text { (cSt) }\end{array}$} & \multirow[t]{2}{*}{ Viscosity index } & \multirow[t]{2}{*}{ Specific gravity $\left(15.6{ }^{\circ} \mathrm{C}\right)$} & \multirow[t]{2}{*}{ Appearance } \\
\hline & & $40^{\circ} \mathrm{C}$ & $100^{\circ} \mathrm{C}$ & $40^{\circ} \mathrm{C}$ & $100^{\circ} \mathrm{C}$ & & & \\
\hline PAO-4 & 0.80 & 14 & 3 & 16.8 & 3.9 & 111 & 0.8190 & Clear and bright \\
\hline
\end{tabular}


Table 3 Major constituent elements of ball and disc material (wt $\%$ )

\begin{tabular}{llllllllll}
\hline & $\mathrm{Fe}$ & $\mathrm{Cr}$ & $\mathrm{C}$ & $\mathrm{Mn}$ & $\mathrm{Si}$ & $\mathrm{P}$ & $\mathrm{S}$ & $\mathrm{V}$ \\
\hline EN-31 steel (disc) & 96.8 & 1.191 & 0.951 & 0.66 & 0.283 & 0.014 & 0.018 & 0.015 & 0.007 \\
AISI 52100 (ball) & 95.5 & 1.3 & 0.95 & 0.25 & 0.15 & 0.03 & 0.025 & 0.01 & 0.025 \\
\hline
\end{tabular}

thickness of $5.315,5.647,6.149$ and $7.113 \mathrm{~nm}$ was obtained corresponding to a load of $80,60,40$ and $20 \mathrm{~N}$, respectively. Based on the minimum film thickness $\left(h_{\min }\right)$ and composite surface roughness $\left(\sigma^{*}\right)$, the $\lambda$-ratio $\left(h_{\min } / \sigma^{*}\right)$ was obtained. For all the conditions considered in this study, $\lambda$ was less than 1 , which conformed with the boundary lubrication regime. Lubrication at the interface was provided in a dropwise manner at the start of the experiment. Samples were cleaned ultrasonically before the start and after the end of every experiment. To ensure the repeatability, all the tests were performed three times.

\section{Surface analysis}

The wear is evaluated according to wear scar diameter on the surfaces of the steel ball and by finding out the wear volume. The diameters of wear spots were measured using an optical microscope. Each reported wear volume is the average of all the three repeated tests. Surface analysis of the wear tracks to identify the wear behavior of lubricants on the disc surfaces was done by scanning electron microscopy. The chemical content of the selected wear tracks on the disc was obtained by energy dispersive X-ray spectroscopy (EDS) to ensure the presence of the corresponding elements.

\section{Results and discussions}

Few studies pertaining to the synergetic effect of nanodiamonds have been reported earlier (Nunn et al. 2015). To explore the synergism of diamond nanoparticles with other nano additives, this study has been carried out. Investigations performed herein have been divided into two sections which include PAO base oil containing $\mathrm{CuO}$ and $\mathrm{CuO} / \mathrm{ND}$ additives and h-BN and h-BN/ND additives.

\section{$\mathrm{CuO}$ and $\mathrm{CuO} / \mathrm{ND}$ additives in base oil}

\section{Tribological studies}

Initially, the performance of $\mathrm{CuO}$ and diamond nanoparticles in PAO base oil was evaluated; thereafter similar tests were performed with $\mathrm{CuO} / \mathrm{ND}$ as nano additives. The results were compared with the base oil results obtained under the same testing conditions. Experiments were performed for five different loads. Figures 1 and 2 gives the variation of coefficient of friction with the number of cycles for low loading $(20 \mathrm{~N})$ and high loading conditions $(100 \mathrm{~N})$, respectively.

For pure PAO oil, the coefficient of friction at low loads shows substantially large variations with time; it first increases and then tends to decrease with a maximum value close to $\sim 0.14$. This increase in friction coefficient may be attributed to the interaction of asperities during the running in period. The onset of steady state is indicated by the increase in stability after 500 cycles. For higher loads, this variation in COF is not much; instead, a sharp peak was observed after 700 cycles. This is certainly due to the enhanced metal to metal contact which is essentially due to the failure of lubricant film. Initially, the coefficient of friction also increases with the addition of $\mathrm{CuO}$ in the base oil at low loads, but its average value is comparatively less $\sim 0.11$. Moreover, it takes more time to attain a steady state in comparison to the pure base oil. This may be attributed to the delay in onset of the steady-state condition due to interaction of sharp asperities and delay in the film formation by the $\mathrm{CuO}$ nanoparticles. Once the sharp asperities gets smoothened and a protective layer is formed, the coefficient of friction tends to attain stability. For higher loads, it attains steady state comparatively in less time. The COF for the oil containing ND is slightly less than PAO and PAO + $\mathrm{CuO}$ oil, for both the loading conditions. At a load of $20 \mathrm{~N}$, the mean COF is $\sim 0.10$ and the

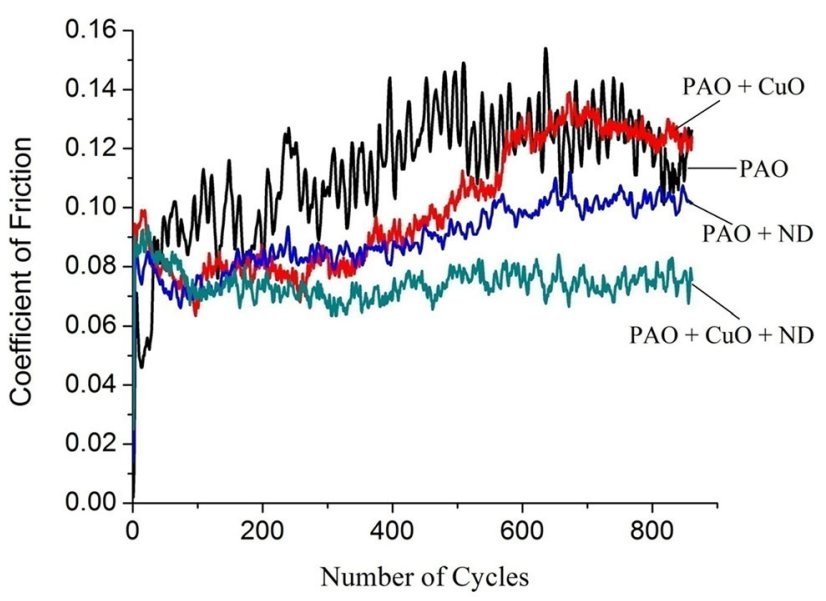

Fig. 1 Frictional behavior of different lubricants at $20 \mathrm{~N}$ load 


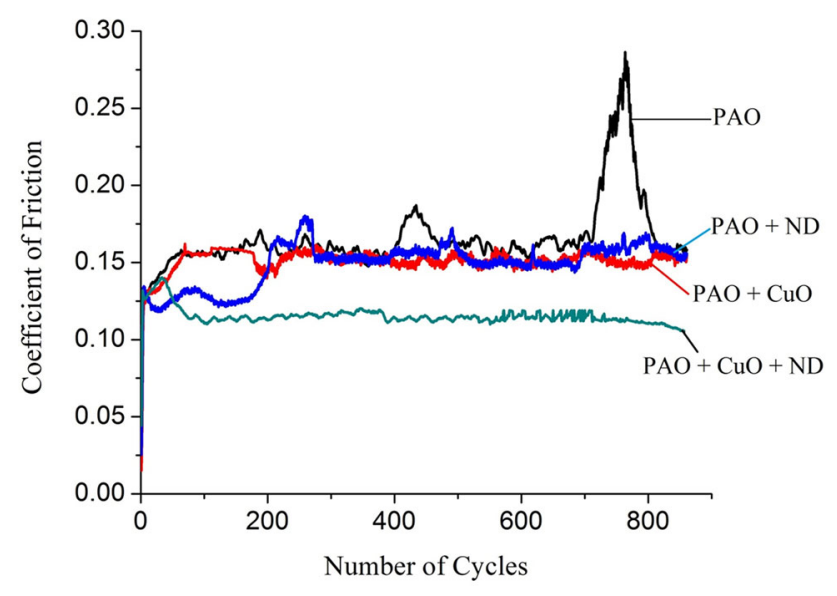

Fig. 2 Frictional behavior of different lubricants at $100 \mathrm{~N}$ load

time for attaining steady state is also more. But for the load of $100 \mathrm{~N}$, the steady state was obtained after 250 cycles, and thereafter a stable value of friction coefficient was obtained. The behavior of lubricant containing $\mathrm{CuO} / \mathrm{ND}$ is different from the above two lubricants and tends to attain stability more quickly. For lower loads, the coefficient of friction is nearly 0.09 . This is due to the combined effect of both the nanoparticles. The nanodiamond being hard in nature has the capability to smoothen the sharp asperities in less time, due to which the running time gets reduced and stability in the friction coefficient can be attained. For higher loads, the coefficient of friction is $\sim 0.135$ and the variation of $\mathrm{COF}$ with respect to the number of cycles is also somewhat similar to lower loads. Thus, it is evident that the friction coefficient of $\mathrm{CuO} / \mathrm{ND}$ oil is considerably less in comparison to base oil, $\mathrm{CuO}$ oil and ND oil.

The values of the friction coefficient obtained at different loads are shown in Fig. 3. It can be observed that the coefficient of friction increases with increase in load. For a lubricant containing $\mathrm{CuO}$, previous studies reveal that only a thin layer of lubricant can be maintained in the boundary lubrication regime and the direct contact between asperities

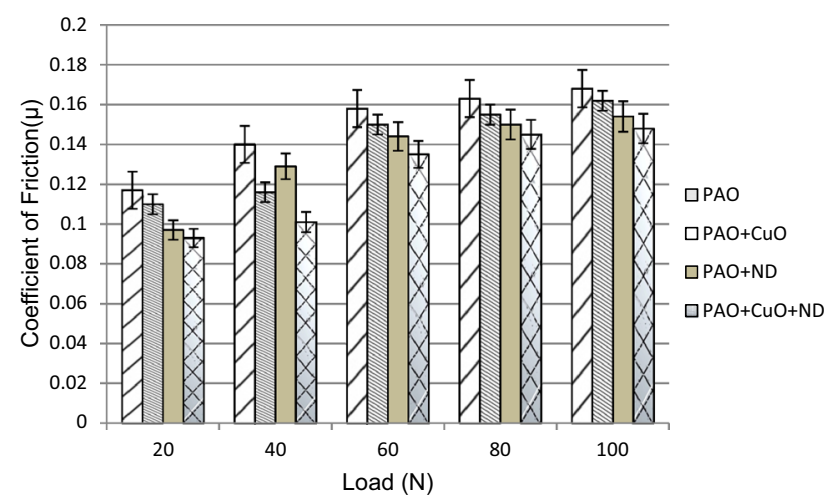

Fig. 3 Coefficient of friction corresponding to different loads plays a dominant role (Jatti and Singh 2015). The increase in the coefficient of friction with increase in load is therefore due to the increased interaction between the asperities of two sliding surfaces. However, on addition of nanodiamonds, restriction in free rolling of hard diamond nanoparticles with the increase in load may be the possible reason behind increased coefficient of friction (Novak et al. 2014).

When the lubricant containing $\mathrm{CuO}$ nanoparticles is used, the coefficient of friction is less at all the loads in comparison to the case when there are no additives in the oil. At $20 \mathrm{~N}$ load, the decrease in friction coefficient is $5.98 \%$, whereas at $100 \mathrm{~N}$ load the decrease is $4.76 \%$. Similarly, on the addition of ND in PAO base oil, there is an improvement in COF in comparison to the PAO base oil. However, for the lubricant blended with $\mathrm{CuO} / \mathrm{ND}$, a substantial reduction can be observed. The friction coefficient is decreased by $15.45 \%$ corresponding to a load of $20 \mathrm{~N}$ in comparison to oil containing $\mathrm{CuO}$ nanoparticles alone. Similar kinds of results were obtained for other higher loads also. The decrease in the friction coefficient at a load of $100 \mathrm{~N}$ is $8.64 \%$. The reason for the decrease in the friction coefficient for the first and second case is attributed to the rolling effect caused by the $\mathrm{CuO}$ and diamond nanoparticles (Peña-Parás et al. 2014). But for the third case, the reduction in friction coefficient is certainly due to the combined effect of $\mathrm{CuO}$ and diamond nanoparticles. Earlier studies have reported that these particles provide a ball bearing effect, which leads to the decrease in the friction coefficient (Kim et al. 2016; Marko et al. 2015). Apart from this, some researchers report that diamond nanoparticles being hard in nature also provide the polishing effect (Shenderova et al. 2014). Due to this, there is a decrease in the asperity heights, which further reduces the chances of metal to metal contact (Mochalin et al. 2012). The smoothness and layer formation observed in Fig. 7a confirms the same.

Wear was evaluated by calculating the wear volume for each experiment as shown in Fig. 4. The worn-out surfaces of the steel balls are shown in Fig. 5. For the case, when there is no additive in the lubricant, the increase in wear with the increase in load is due to wear caused by the adhesion of asperities (Peng et al. 2009a, b). On the increase in the load, asperity to asperity contact increases, thereby increasing the damage at the surface and can be observed in Fig. 6b. The surface of the disk samples has been delaminated, thereby showing the signs of adhesive wear. However, the use of $\mathrm{CuO}$ nano additives in the lubricant increases wear resistance at all considered loads. In Fig. 7a, the surface damage is comparatively less than in Fig. $6 \mathrm{a}$ and the wear in this case may also be attributed to the adhesive action of the asperities. Previous studies have reported the protective film formation capability of the 


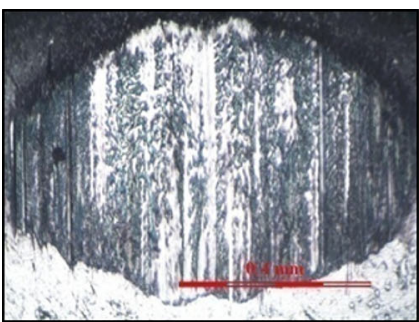

(a)

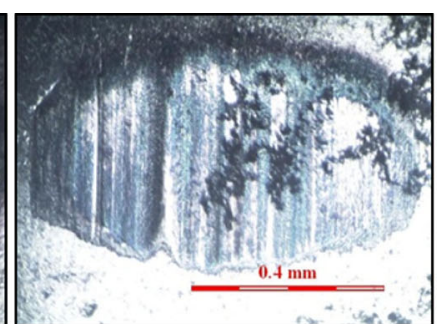

(b)

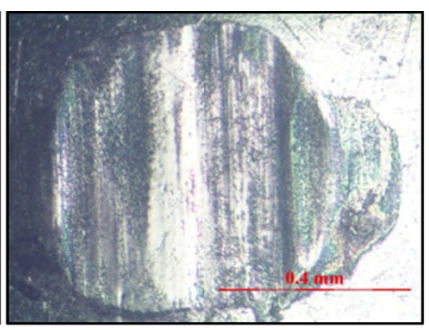

(c)

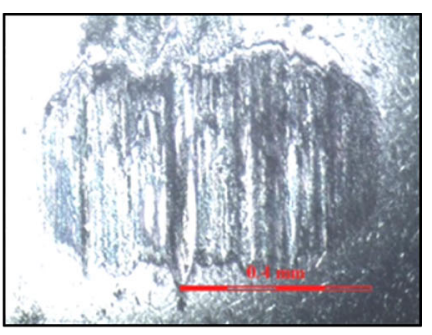

(d)

Fig. 4 Wear scar on the steel balls at a load of $100 \mathrm{~N}$ for a PAO base oil, $\mathbf{b}$ PAO $+\mathrm{CuO}$ oil, $\mathbf{c}$ PAO $+\mathrm{ND}$ oil and $\mathbf{d}$ PAO $+\mathrm{CuO}+\mathrm{ND}$ oil

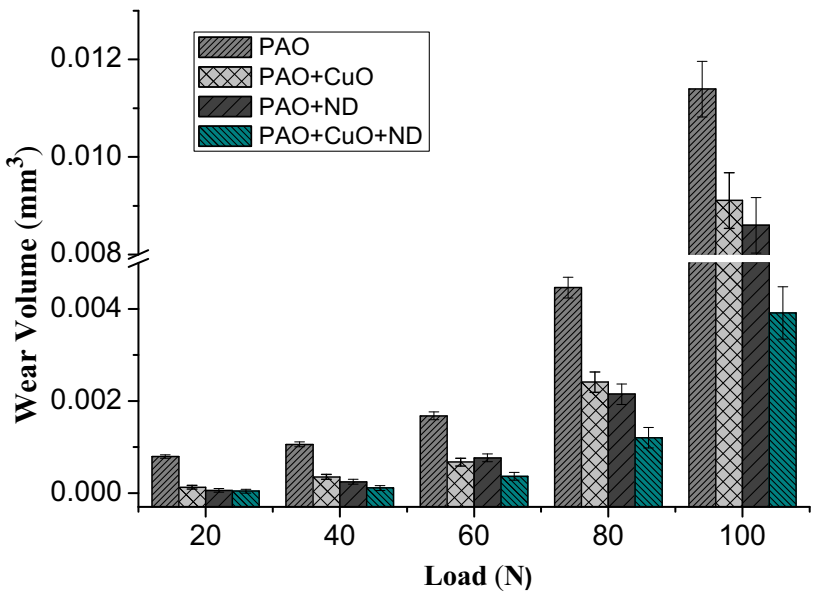

Fig. 5 Wear volume corresponding to different loads

$\mathrm{CuO}$ nanoparticles. The decrease in wear volume in this case also is due to the deposition of nanoparticles on the worn surfaces (Peña-Parás et al. 2015; Thottackkad et al. 2014). For the oil containing diamond nanoparticles only, there is also a reduction in wear volume. This reduction is, however, more at the low loads in comparison to the higher loads. This may be attributed to restriction in the free rolling of the hard nanoparticles at the increased loads. The use of lubricating oil blended with $\mathrm{CuO}$ and diamond nanoparticles further reduced the wear volume. At $20 \mathrm{~N}$ load, the wear volume is $67.71 \%$ less in comparison to the lubricating oil blended with $\mathrm{CuO}$ nanoparticles alone, whereas for $100 \mathrm{~N}$ load the same is reduced by $57.03 \%$. The decrease in wear volume is due to the polishing effect of the diamond nanoparticles and subsequent protective film formation capability of the $\mathrm{CuO}$ nanoparticles (Nunn et al. 2015; Shenderova et al. 2014). The same can be observed in Fig. 8a, which shows an overall improvement in the surface properties. The continuous delamination is absent and only fine grooves are visible, indicating the abrasive action of diamond nanoparticles, whereas in Fig. $8 \mathrm{~b}$ some patches can also be observed suggesting the surface damage due to adhesion. The wear in this case is due to both adhesion and abrasion.

\section{Surface analysis}

Figure 6a shows the SEM images of the worn-out surface of the disc samples for PAO base oil at $100 \mathrm{~N}$ load. It can be observed that the surface is comparatively rough, suggesting plastic deformation at some places. Figure $6 \mathrm{~b}$ gives the enlarged version of Fig. 6a, wherein delamination wear can also be observed which is caused due to the removal of a thin layer from the metal surface. EDS spectra (Fig. 6c) of the worn-out surfaces indicate the presence of similar elements in almost the same percentage, thereby suggesting that no other element is present on the surface other than the constituent elements of the ball and disc materials. For the oil blended with $\mathrm{CuO}$ nanoparticles, surface damage is comparatively different (Fig. 7a). The wear in this case may be attributed to the scuffing damage caused by the adhesive action of the asperities due to the stick and slip behavior of the interacting surfaces (Mordukhovich et al. 2013). However, a thin layer in this case can also be observed suggesting the film formation capability of $\mathrm{CuO}$ nanoparticles (Padgurskas et al. 2013). Figure 7b indicates the enlarged version of the surface damage and layer formation on the worn surfaces. The EDS spectra (Fig. 7c) of the worn-out surfaces shows a peak of $\mathrm{Cu}$ element, thereby confirming the presence of $\mathrm{CuO}$ on the worn-out surfaces. However, for the lubricant containing both $\mathrm{CuO}$ and $\mathrm{ND}$, some fine grooves can be observed on the wear track suggesting the rolling action of hard diamond nanoparticles (Fig. 8a). Moreover, the wear behavior in this case is entirely different from the previous one. The wear in this case may be attributed to ploughing with layer formation. Some particles have come out at certain places, but layer formation is predominant. This is entirely due to the antiscuffing properties of the diamond nanoparticles. The daubed corners (Fig. 8b) also confirm the film formation capability of the $\mathrm{CuO}$ nanoparticles. The EDS spectra shown in Fig. 8c confirm the presence of $\mathrm{CuO}$ and ND on the worn-out surfaces of the disc samples.

Figure 9 shows the SEM image of the worn-out surface corresponding to low loading condition $(20 \mathrm{~N})$ for a sample lubricated with PAO base oil. It can be observed that there 
Fig. 6 a SEM image of wear track lubricated with PAO base oil corresponding to a load of $100 \mathrm{~N}, \mathbf{b}$ magnified image $(\times 5000)$ of $\mathbf{a}$ and $\mathbf{c}$ EDS of figure (a)

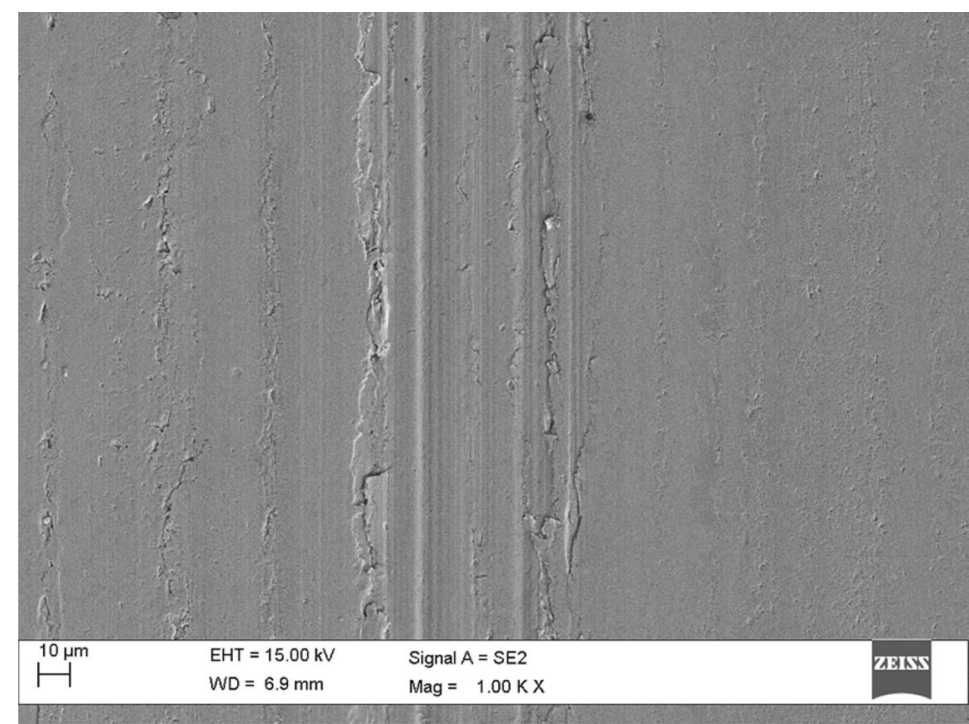

(a)

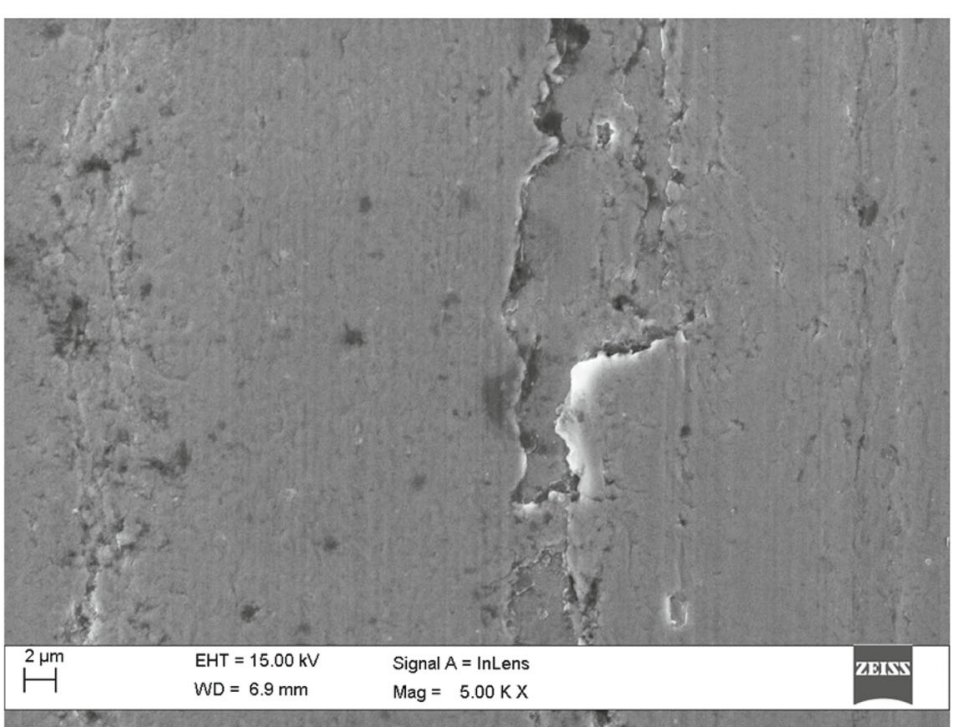

(b)

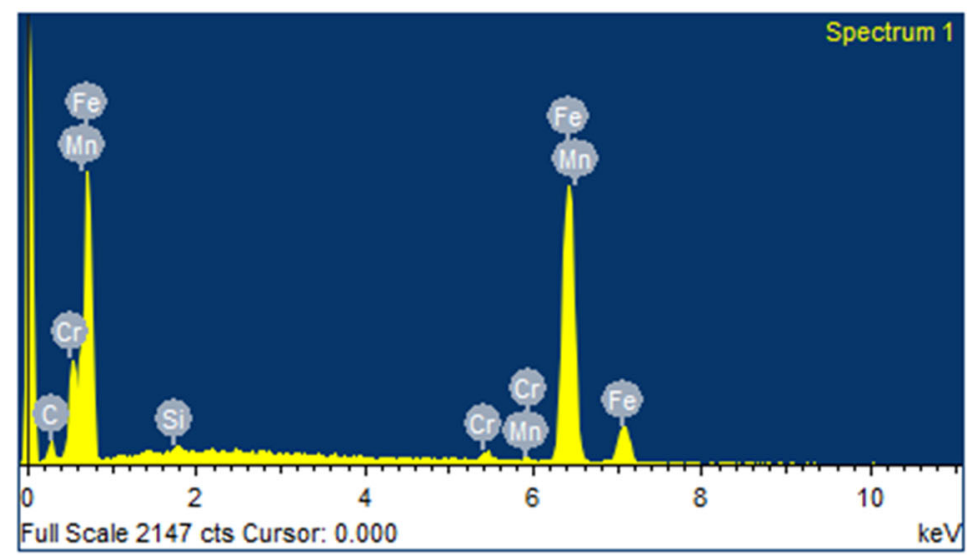

(c) 
Fig. 7 a SEM image of wear track lubricated with

$\mathrm{PAO}+\mathrm{CuO}$ oil corresponding to a load of $100 \mathrm{~N}, \mathbf{b}$ magnified image $(\times 5000)$ of $\mathbf{a}$ and $\mathbf{c}$ EDS of figure (a)

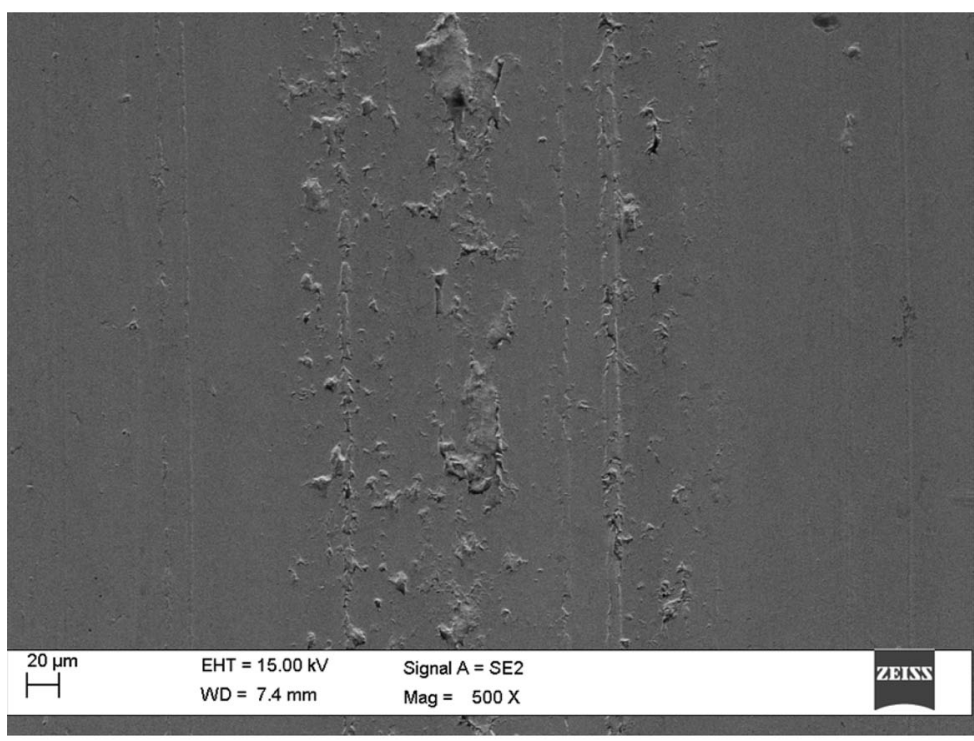

(a)

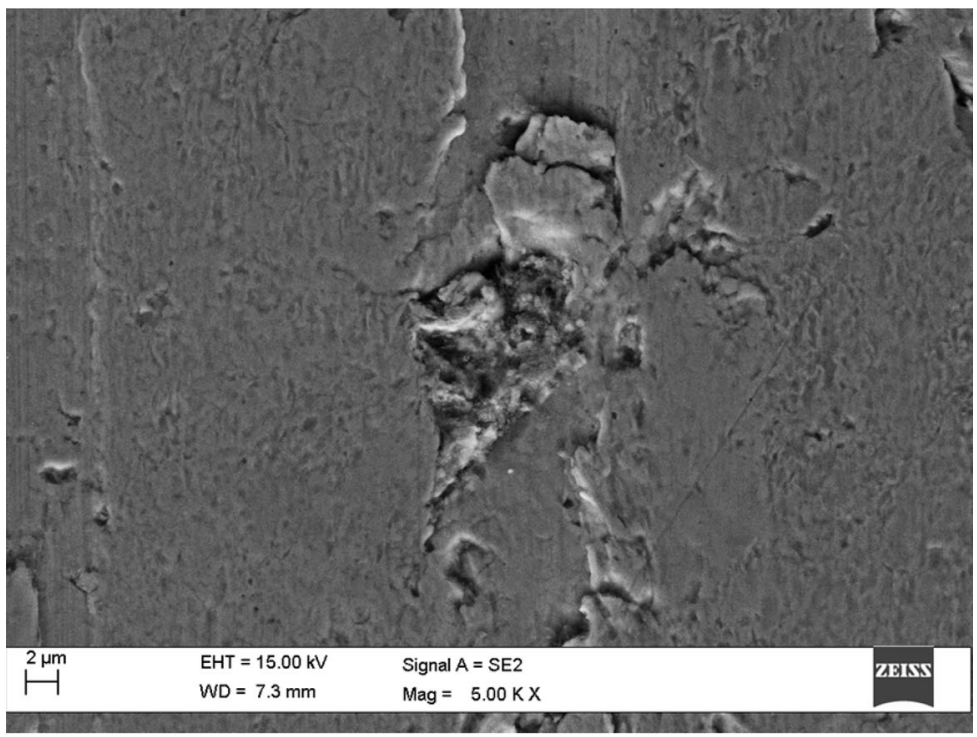

(b)

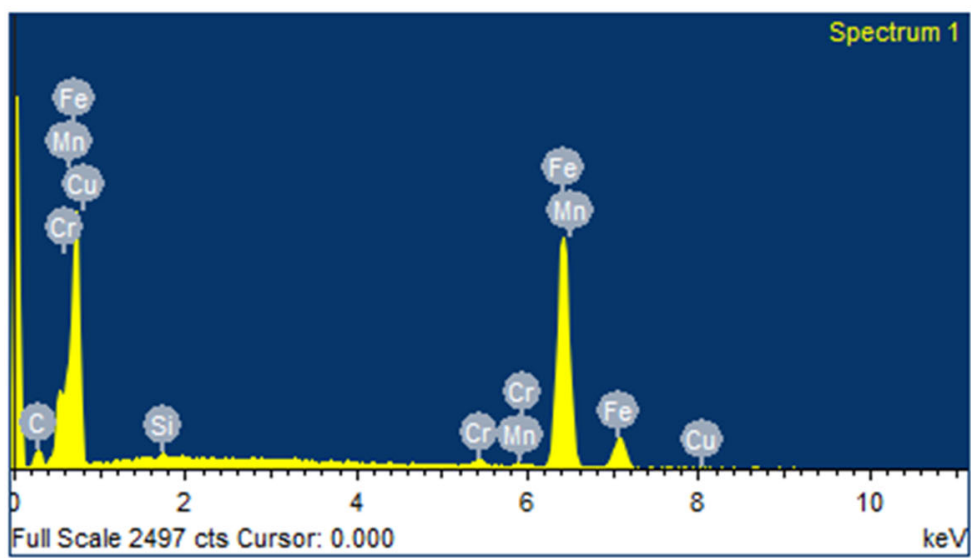

(c) 
Fig. 8 a SEM image of wear track lubricated with $\mathrm{PAO}+\mathrm{CuO}+\mathrm{ND}$ oil corresponding to a load of $100 \mathrm{~N}$, b magnified image $(\times 5000)$ of $\mathbf{a}$ and $\mathbf{c}$ EDS of figure (a)

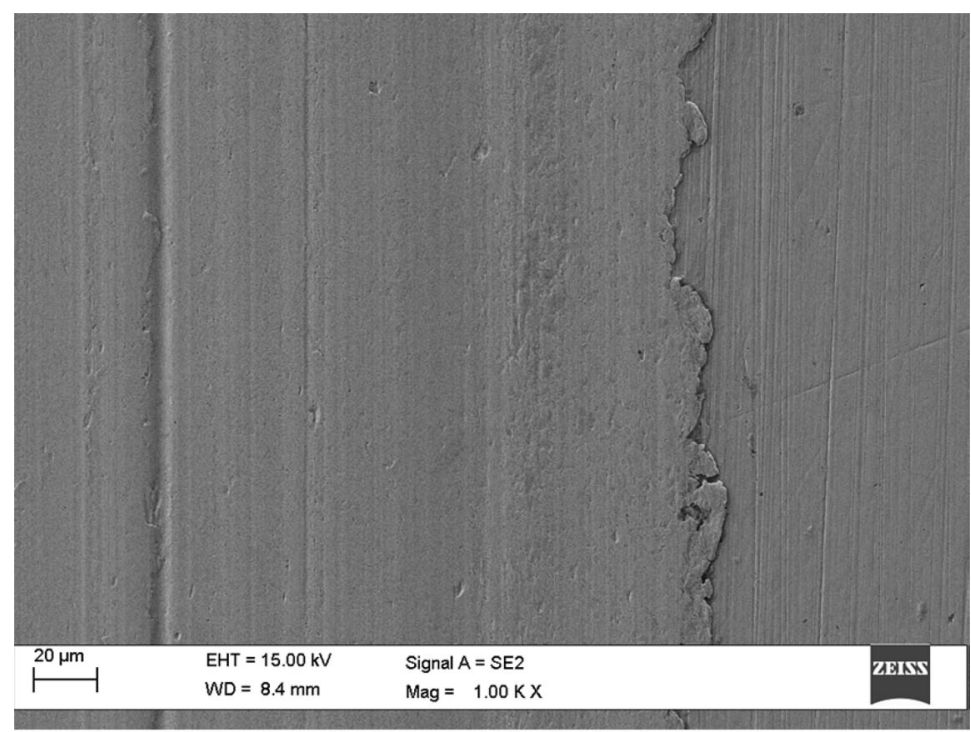

(a)

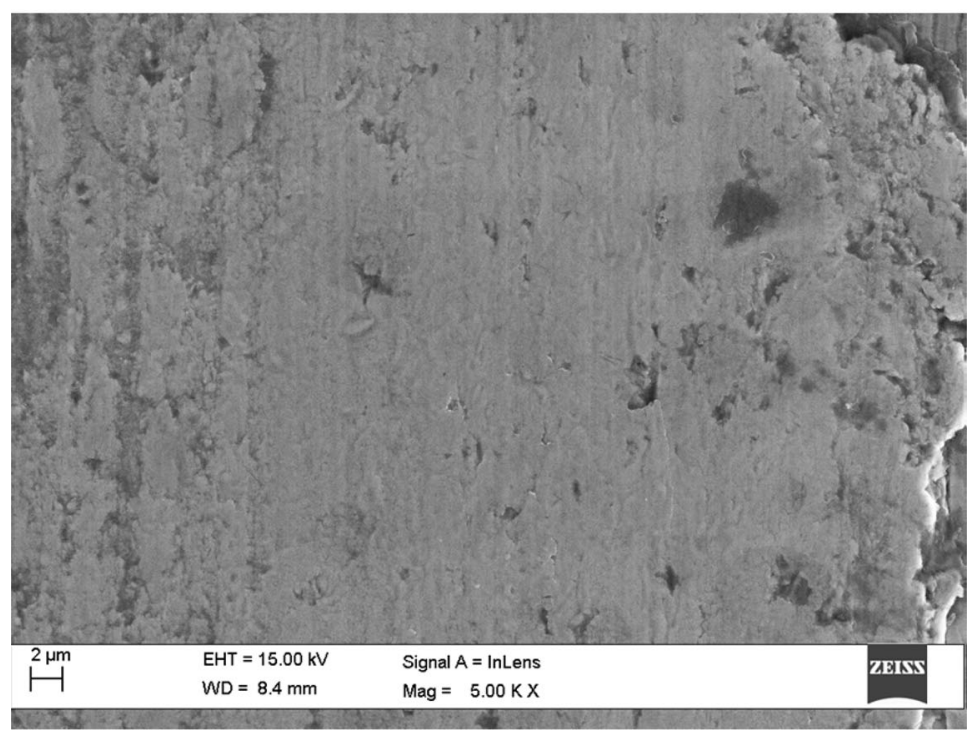

(b)

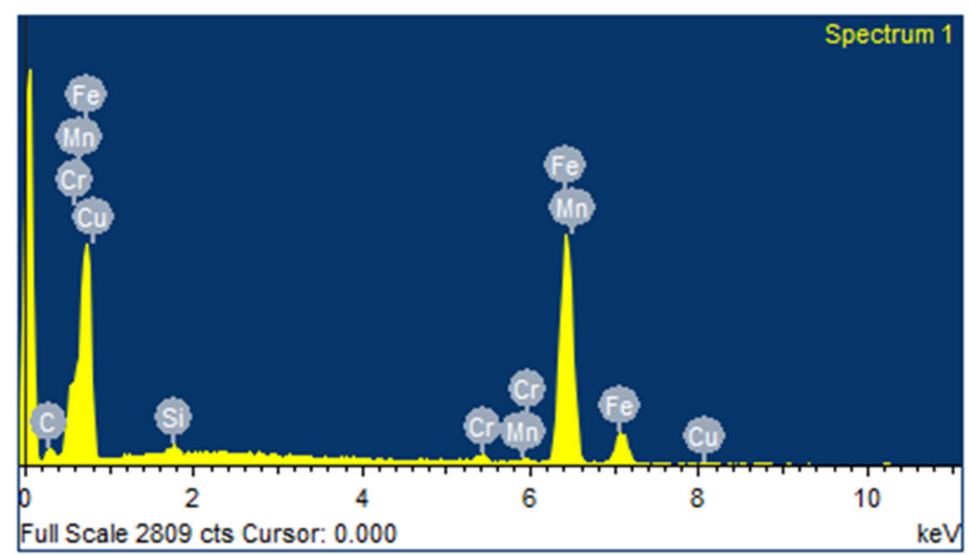

(c) 


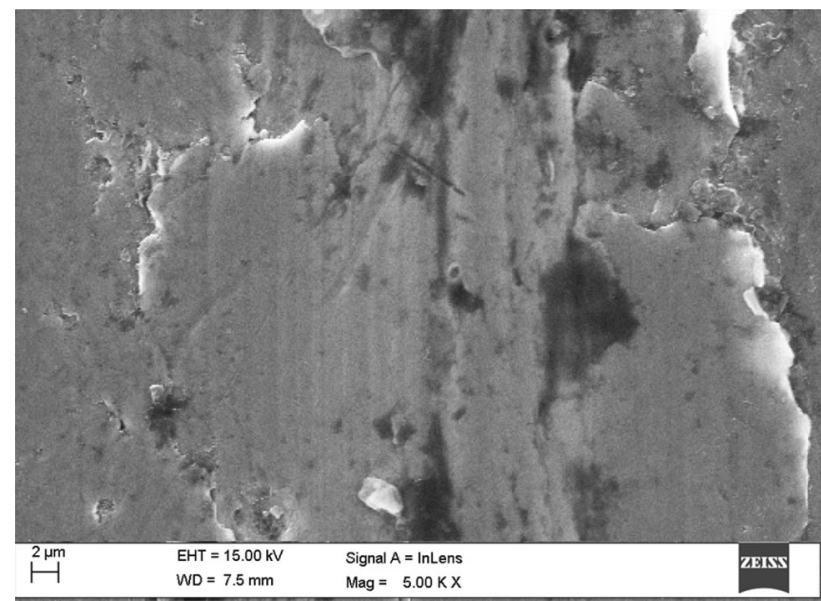

Fig. 9 SEM image for wear track lubricated with PAO base oil corresponding to a load of $20 \mathrm{~N}$

is a substantial amount of wear on the surface. This damage may be attributed to the delamination of layers from the steel surface, which is due to the adhesion of asperities that ultimately leads to the removal of layers. In contrast to this (Fig. 10), there is less delamination of layers, with the use of $\mathrm{CuO}$ nanoparticles in the base oil. The improvement in the wear may be attributed to the effect of $\mathrm{CuO}$ nanoparticles. The film formation capability as discussed previously is the possible reason for the reduced wear. The SEM image of the worn-out surface lubricated with oil containing $\mathrm{CuO} / \mathrm{ND}$ nanoparticles is shown in Fig. 11. It can be observed that severe delamination has been reduced and only few scars are present on the surface. Also, it can be observed that there are some parallel grooves on the surface in the sliding direction. These grooves on the surface are due to the inclusion of ND particles in the oil which have caused some abrasion owing to their hard nature. It can be observed that the combination of $\mathrm{CuO}$ and $\mathrm{ND}$ has

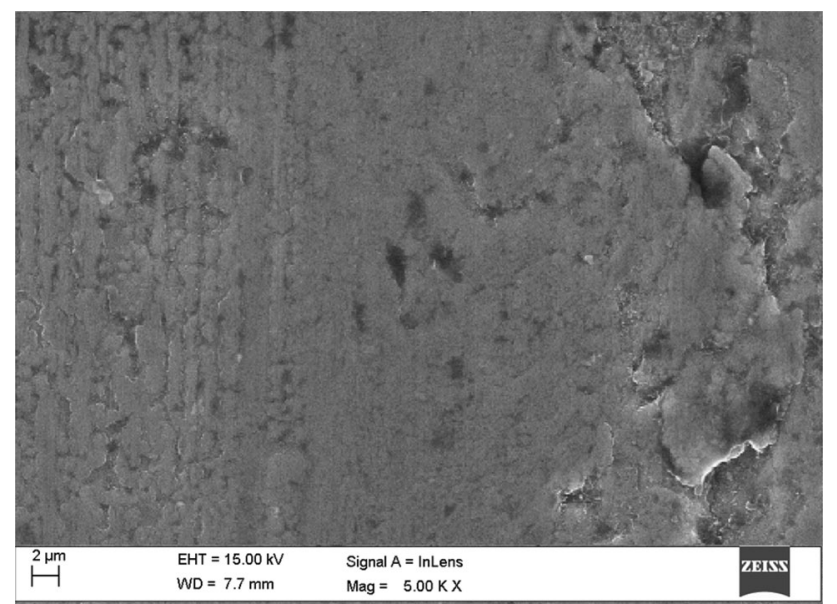

Fig. 10 SEM image for wear track lubricated with $\mathrm{PAO}+\mathrm{CuO}$ oil corresponding to a load of $20 \mathrm{~N}$

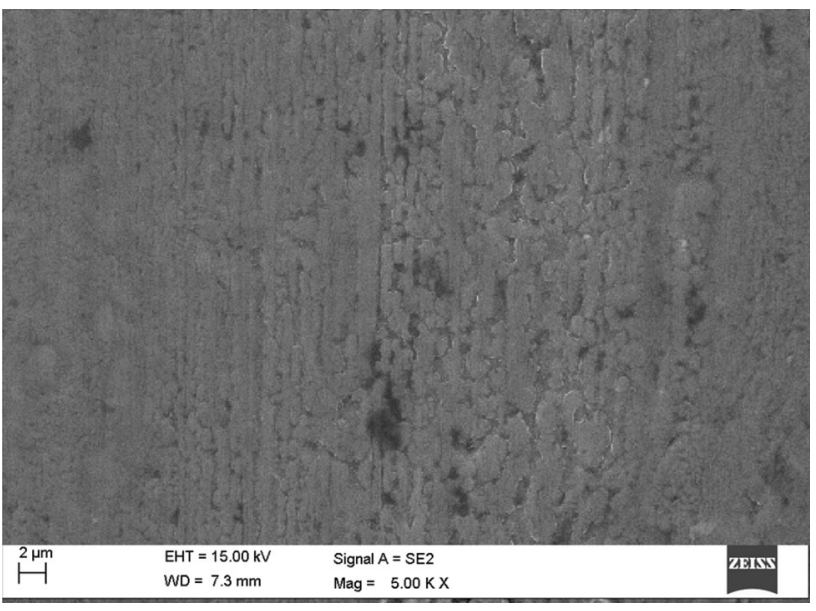

Fig. 11 SEM image for wear track lubricated with PAO + $\mathrm{CuO}+\mathrm{ND}$ oil corresponding to a load of $20 \mathrm{~N}$

reduced the delamination of surfaces, but there is an increase in the abrasive wear. The combined effect of this is that there is an overall improvement in the wear characteristics.

\section{$h-B N$ and $h-B N / N D$ additives in base oil}

\section{Tribological studies}

Figures 12 and 13 give the variation in coefficient of friction corresponding to the number of cycles for low loading $(20 \mathrm{~N})$ and high loading conditions $(100 \mathrm{~N})$, respectively. On addition of h-BN in base oil, the coefficient of friction increases initially for both the loading conditions. For lower loads $(20 \mathrm{~N})$, the coefficient of friction tends to decrease after an initial increase, thus indicating a smaller running period. The decrease in the COF may be attributed to the intrinsic characteristics of the h-BN nanoparticles. Owing to the lamellar structure, the

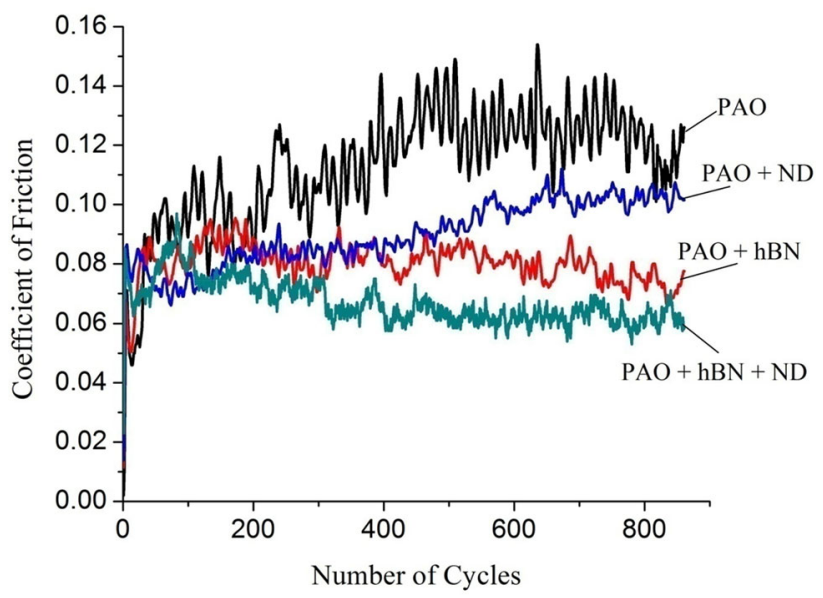

Fig. 12 Frictional behavior of different lubricants at $20 \mathrm{~N}$ load 


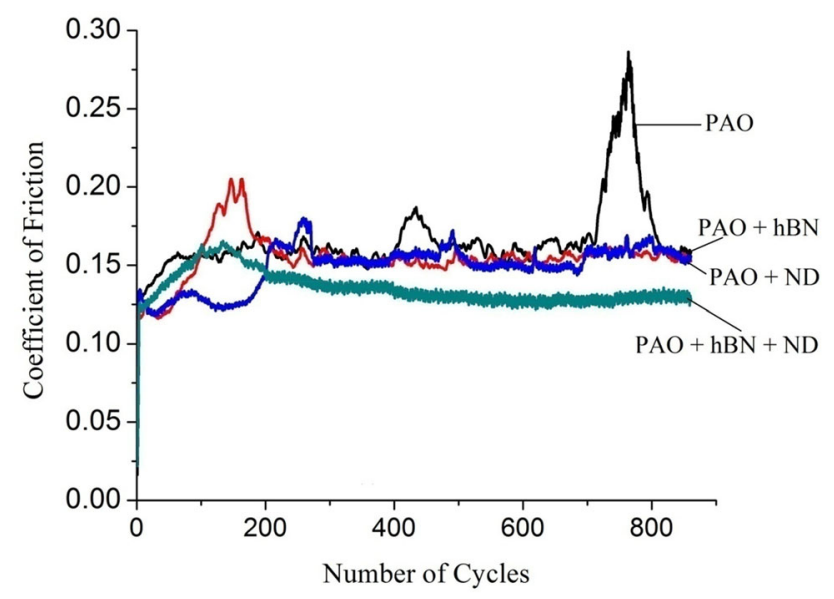

Fig. 13 Frictional behavior of different lubricants at $100 \mathrm{~N}$ load

layers of h-BN get easily deformed, thus reducing the frictional resistance between the two sliding surfaces. The increase in COF at the start is more for high loads, but after 180 cycles it tends to decrease. This is due to the film formation capability of the h-BN nanoparticles, which prevents the metal to metal contact. The oil containing ND particles also showed an improvement in COF, but less in comparison to the oil containing h-BN nanoparticles. Also, the running in time is comparatively more. The behavior of lubricant containing $\mathrm{h}-\mathrm{BN} / \mathrm{ND}$ is even better than the lubricant containing h-BN nanoparticles alone. The average frictional coefficient at $20 \mathrm{~N}$ load is $\sim 0.08$, which is much lower than h-BN containing lubricant. After 100 cycles, the coefficient of friction starts decreasing and tends to obtain a steady state condition. The combined effect of both the nanoparticles is the major cause for the better lubrication properties (Fig. 14).

Figure 11 gives the friction coefficient corresponding to different loads. The coefficient of friction increases with increase in the load for all the lubricants. The increase in the coefficient of friction with increase in the load for pure base oil is due to increased metal to metal contact that leads

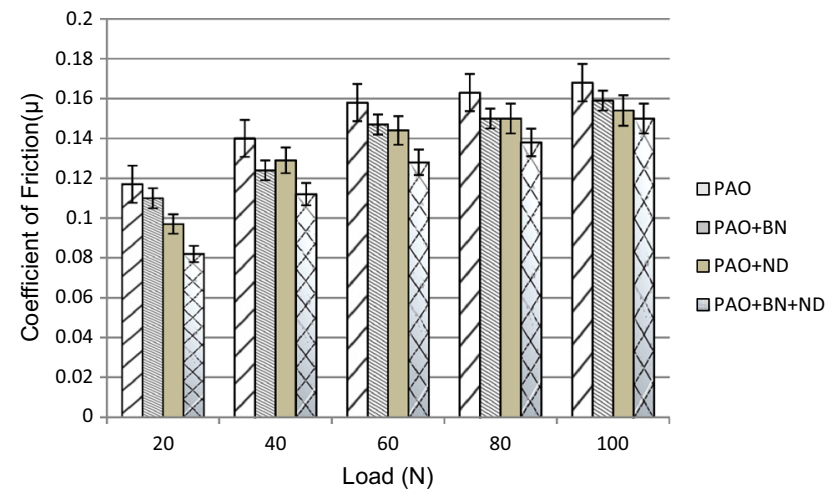

Fig. 14 Coefficient of friction corresponding to different loads to the adhesion of micro asperities. For a lubricant containing h-BN nanoparticles, the friction coefficient is comparatively less at the corresponding loads. This is due to the stable film formation capability of the boron element present in the boron nitride nanoparticles (Abdullah et al. 2016), which is also shown in Fig. 17b. Apart from this, the layered structure and softness of h-BN provide better lubrication properties (Çelik et al. 2013). The decrease in the friction coefficient is $5.98 \%$ at $20 \mathrm{~N}$, whereas for $100 \mathrm{~N}$ load the decrease is $5.35 \%$. For the ND oil, the COF is also less in comparison to the PAO base oil. This is due to the rolling effect of diamond nanoparticles. But for the lubricant blended with h-BN/ND there is a substantial decrease in the friction coefficient. A maximum decrease of $25.45 \%$ in friction coefficient is obtained for a load of $20 \mathrm{~N}$ in comparison to $\mathrm{PAO}+\mathrm{h}-\mathrm{BN}$ oil. Similar kinds of results were obtained for the other higher loads considered in the study. The reduction in friction coefficient is due to the combined effect of h-BN and diamond nanoparticles. The entrapment of ND particles in the asperities and the lubricating effect of h-BN lead to the decrease in the friction coefficient (Kim et al. 2016). Apart from this, the smoothening effect of diamond nanoparticles due to their hard nature is one of the possible reasons for decrease in the friction coefficient (Shenderova et al. 2014). This is possible due to the decrease in the asperity heights, which further reduces the chances of metal to metal adhesion (Mochalin et al. 2012) and can be seen in Fig. 18a.

The wear volumes of worn-out surfaces of the steel ball corresponding to variable loads are shown in Fig. 15, whereas the optical images of the wear scar corresponding to a load of $100 \mathrm{~N}$ are shown in Fig. 16. For pure base oil, as described previously, the increase in wear with the increase in load is due to the wear caused by the adhesion of asperities. However, the use of h-BN nano additives in the base oil reduces the wear at all the loads. The reduction

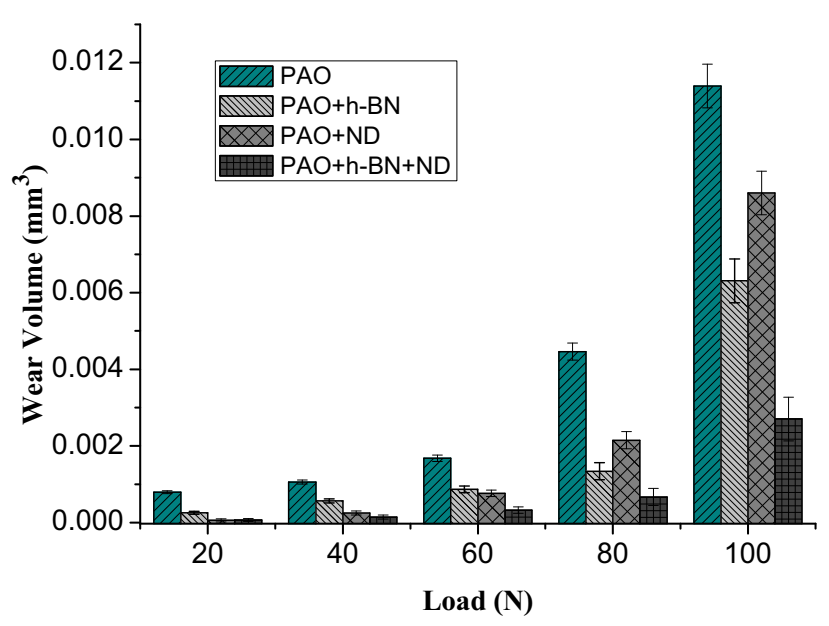

Fig. 15 Wear volume corresponding to different loads

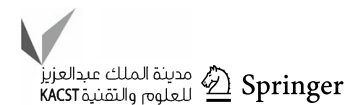


Fig. 16 Wear scar on the steel balls at a load of $100 \mathrm{~N}$ for a PAO + h-BN oil, b $\mathrm{PAO}+\mathrm{h}-\mathrm{BN}+\mathrm{ND}$ oil

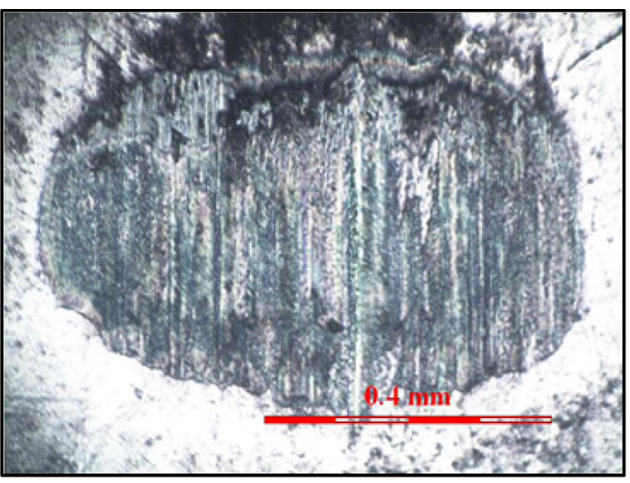

(a)

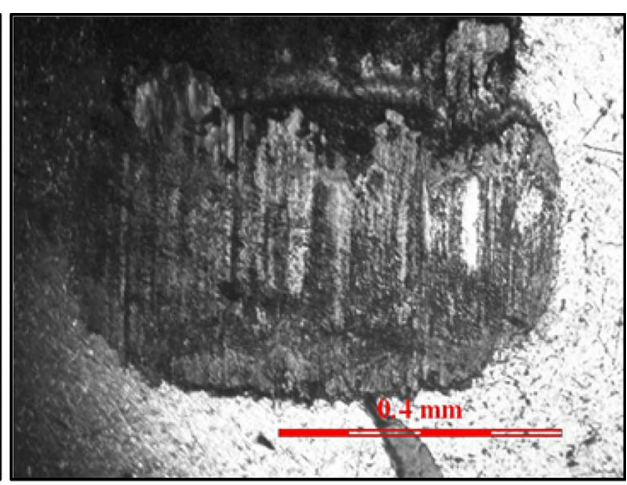

(b) in wear volume is $67.73 \%$ for $20 \mathrm{~N}$ load, whereas for $100 \mathrm{~N}$ it is $44.68 \%$. The decrease in wear volume is due to the increase in the real area of contact by the inclusion of h-BN nanoparticles. Owing to the lamellar structure, h-BN nanoparticles get easily sheared into layers due to weak van der Waals forces. In Fig. 17a also, the surface damage is comparatively less than in Fig. 6a. Also in Fig. 17b, in can be seen that a layer has been formed which prevents metal to metal contact (Çelik et al. 2013). The surface damage in this case may be attributed to adhesive wear. Similar kind of results were also obtained for the oil containing diamond nanoparticles, but it was observed that improvement in the wear volume was less at higher loads as discussed in the previous section, whereas the use of lubricating oil containing h-BN/ND further reduced the wear volume. At $20 \mathrm{~N}$ load, the wear volume is $69.3 \%$ less in comparison to the h-BN lubricant, whereas at $100 \mathrm{~N}$ the same is reduced by $57.16 \%$. The improvement in wear properties is due to the combined effect of the diamond nanoparticles and h-BN layers formed therein (Shenderova et al. 2014; Pawlak et al. 2009). In Fig. 18a also, less surface damage is visible in comparison to that in Fig. 17a. The adhesive wear is almost absent, whereas some grooves caused by the ploughing action of the diamond nanoparticles are visible. The surface damage in this case may be attributed to abrasive wear.

\section{Surface analysis}

Figure 17a shows the SEM images of the worn-out surfaces of the disc samples corresponding to a load of $100 \mathrm{~N}$ for a lubricant containing $\mathrm{h}-\mathrm{BN}$ nanoparticles. It can be observed that a protective film has been formed due to the layered structure and softness of the h-BN nanoparticles (Çelik et al. 2013). The wear in this case may be attributed to the delamination of the film formed therein. Figure $17 \mathrm{~b}$ gives the presence of h-BN particles on the damaged surfaces. Moreover, the peaks (Fig. 17c) of $\mathrm{B}$ and $\mathrm{N}$ on the
EDS spectra also confirm the presence of $h-B N$ on the worn surfaces. For the oil containing a mixture of h-BN and ND, the surface damage is much less as shown in Fig. 18a. The high load-carrying capacity of the diamond nanoparticles seems to prevent the discontinuities in the lubricant film (Vadiraj et al. 2012), and delamination of the surfaces can be reduced to the maximum possible extent (Fig. 18b). The EDS spectra of the worn-out surface also showed the presence of $B$ and $N$ elements.

Figure 19 shows the SEM image of the worn-out surface when lubricated with h-BN oil at low loading conditions $(20 \mathrm{~N})$. It can be observed that surface damage is mainly due to adhesive wear. Severe delamination, which was observed in Fig. 9, is minimum in this case. The improvement in wear may be attributed to the action of h-BN nanoparticles that gets easily sheared on the application of even small loads. The performance of the oil containing h-BN/ND oil is much better than the oil containing h-BN nanoparticles alone. The surface damage as can be seen from Fig. 20 is very much less in comparison to the previous case. The wear spots in the bulk are also absent and only few marks are visible. The wear in this case may be attributed to the adhesion of asperities. The improvement in wear is due to the combined effect of h-BN and ND particles.

\section{Climbing load performance}

For $\mathrm{CuO} / \mathrm{CuO}+\mathrm{ND}$ oil

The climbing load tests were also performed to evaluate the extreme pressure properties of nanodiamonds. The loads were increased in a stepwise manner from 20 to $100 \mathrm{~N}$. Figure 21 gives the frictional characteristics of the lubricants containing $\mathrm{CuO}$ and $\mathrm{CuO} / \mathrm{ND}$ oil with respect to the pure base oil. It can be observed that, at lower loads (20 and $40 \mathrm{~N}$ ), friction force is mostly stable and is minimum for $\mathrm{CuO} / \mathrm{ND}$. But at higher loads, there are sharp peaks for 
Fig. 17 a SEM image of wear track lubricated with $\mathrm{PAO}+\mathrm{h}$ $\mathrm{BN}$ oil corresponding to a load of $100 \mathrm{~N}, \mathbf{b}$ magnified image $(\times 10,000)$ of $\mathbf{a}$ and $\mathbf{c}$ EDS of figure (a)

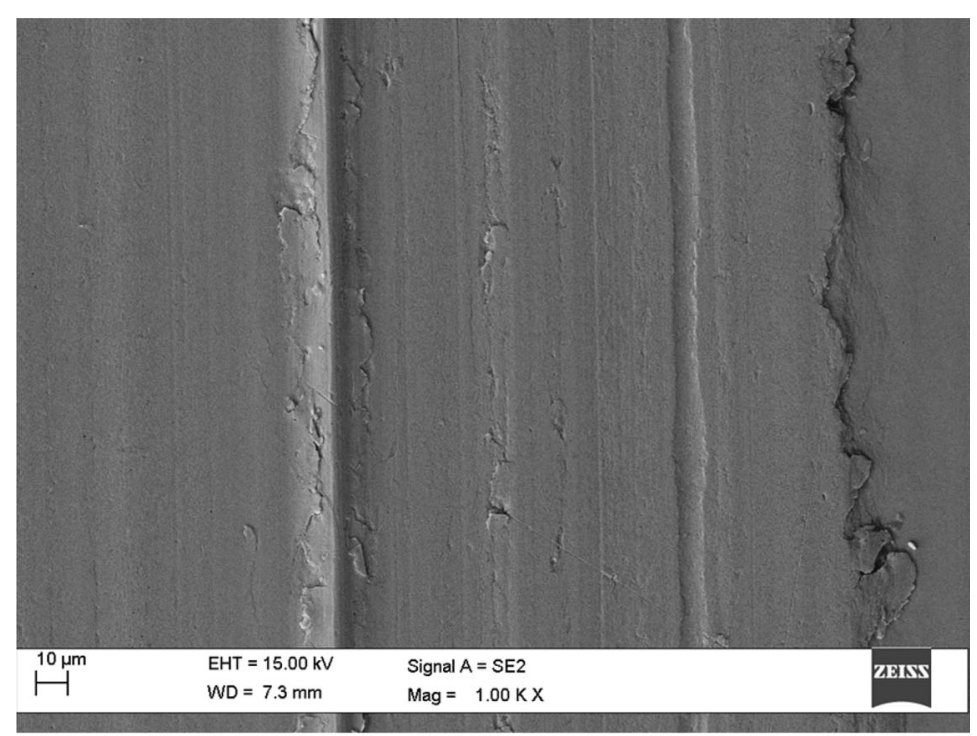

(a)

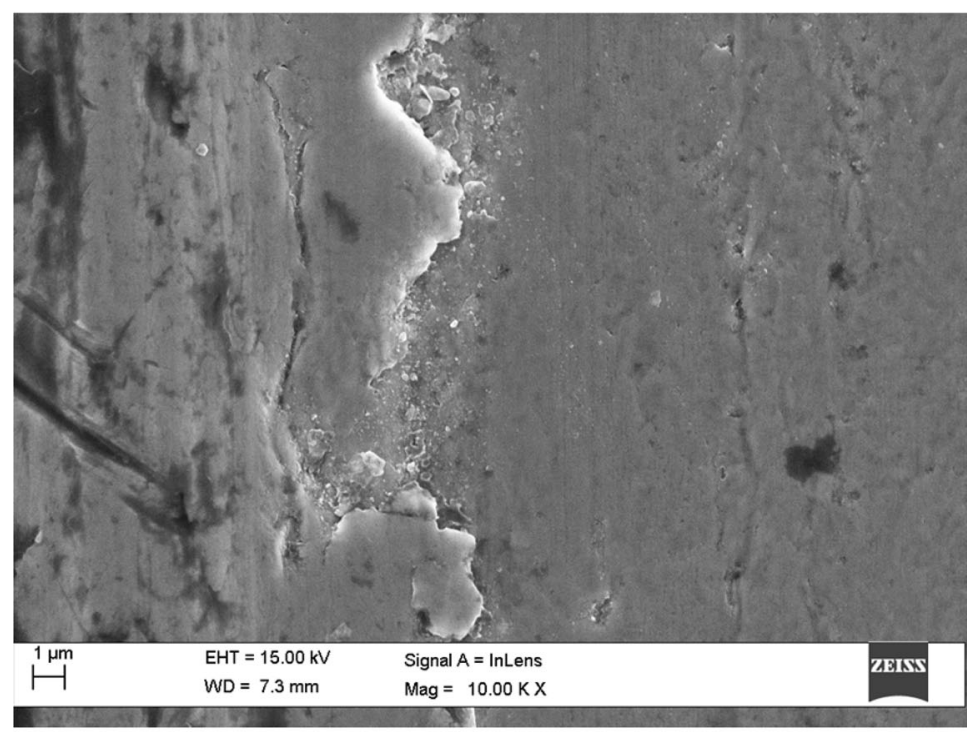

(b)

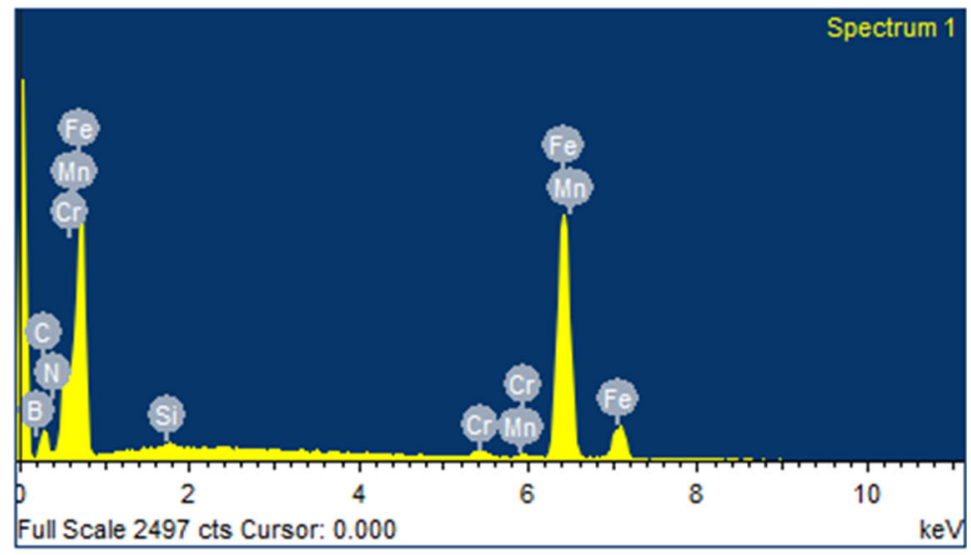

(c) 
Fig. 18 a SEM image of wear track lubricated with $\mathrm{PAO}+\mathrm{h}$ $\mathrm{BN}+\mathrm{ND}$ oil corresponding to a load of $100 \mathrm{~N}, \mathbf{b}$ magnified image $(\times 5000)$ of $\mathbf{a}$ and $\mathbf{c}$ EDS of figure $(\mathbf{a})$

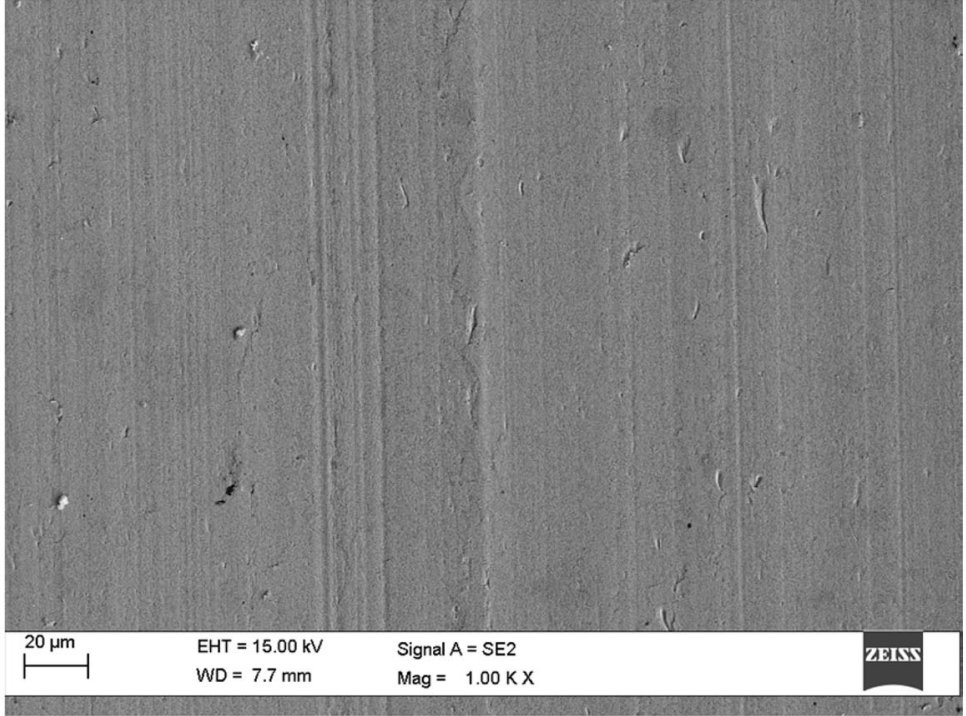

(a)

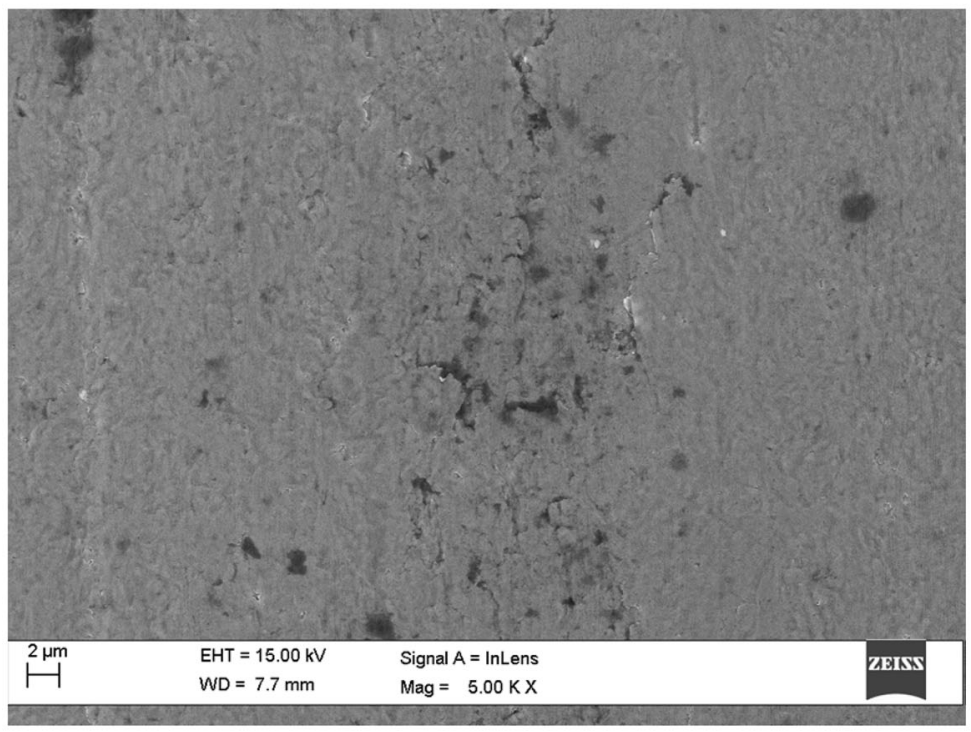

(b)

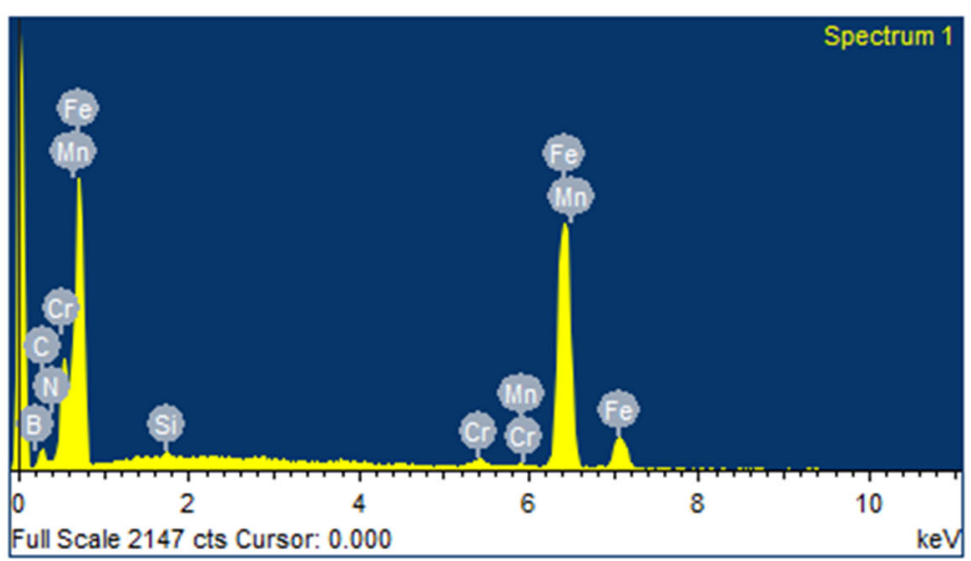

(c) 


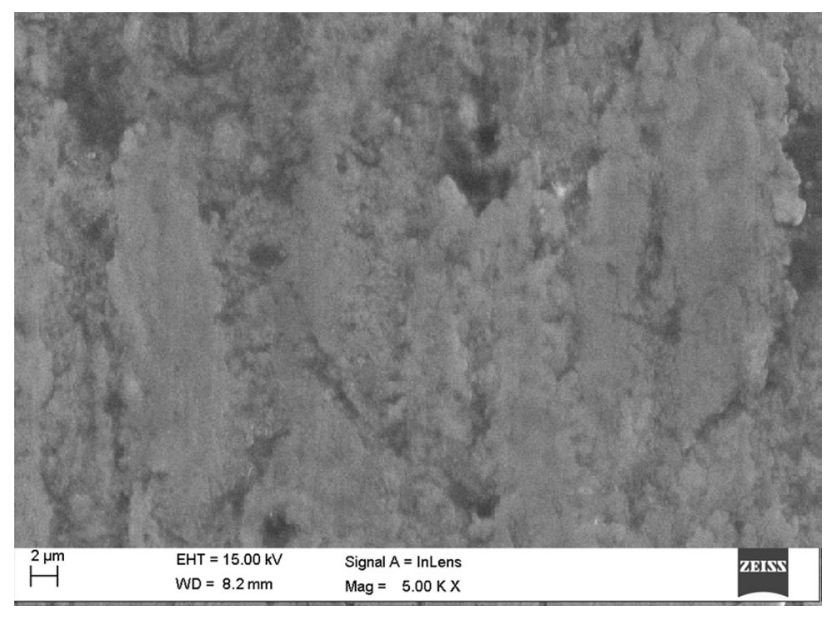

Fig. 19 SEM image for wear track lubricated with $\mathrm{PAO}+\mathrm{h}-\mathrm{BN}$ oil corresponding to a load of $20 \mathrm{~N}$

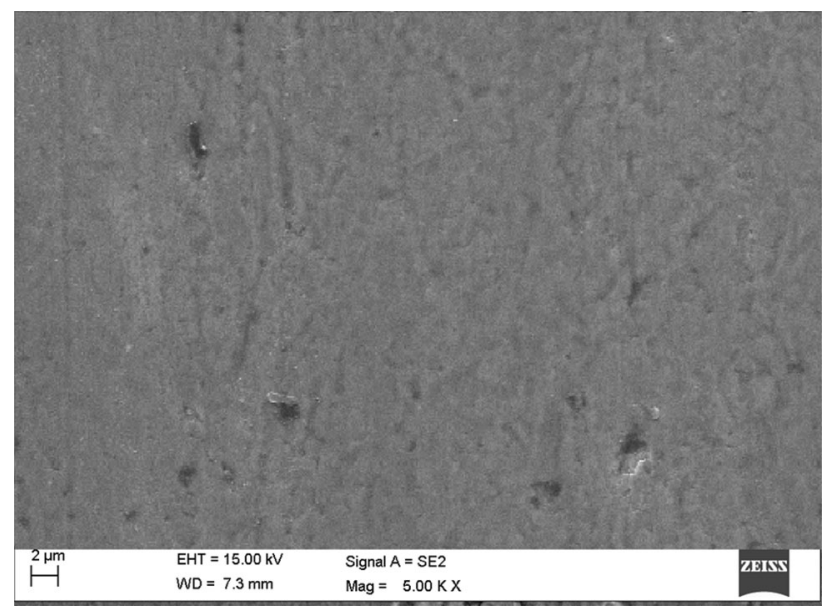

Fig. 20 SEM image for wear track lubricated with $\mathrm{PAO}+\mathrm{h}-$ $\mathrm{BN}+\mathrm{ND}$ oil corresponding to a load of $20 \mathrm{~N}$

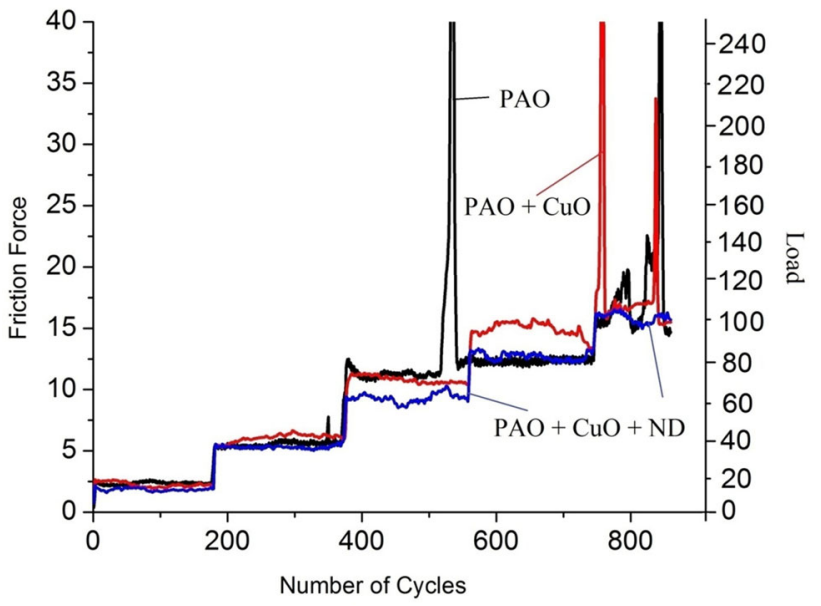

Fig. 21 Frictional force characteristics at different loads increased in a stepwise manner from $20 \mathrm{~N}$ to $100 \mathrm{~N}$ both base oil and $\mathrm{CuO}$ oil. This is due the rupture of lubricant film at the enhanced loads, which leads to the increase in the real area of contact (Vadiraj et al. 2012). However, for $\mathrm{CuO} / \mathrm{ND}$ oil, the frictional force is much stable and no sharp peak was observed. This is due to the extreme pressure capability of the diamond nanoparticles. Moreover, higher thermal conductivity of the diamond nanoparticles enables the lubricant to retain the film even at enhanced loads (Kim et al. 2016). The optical microscope images (as shown in Fig. 22) of the wear scars also reveal that the climbing load characteristics of the lubricant containing $\mathrm{CuO} / \mathrm{ND}$ are much better than those of the base oil itself.

\section{For $h-B N / h-B N+N D$ oil}

Figure 23 gives the frictional characteristics of the lubricants containing h-BN and h-BN/ND additives. At lower loads (20 and $40 \mathrm{~N})$, the frictional force here also is stable and is minimum for h-BN/ND. At higher loads, there are sharp peaks for both PAO base oil and h-BN oil. This is due to the failure of the lubricant film at enhanced loads (Vadiraj et al. 2012). For the lubricant containing h-BN/ND, frictional force here also is much stable and no sharp peak is evident. This is due to the different properties of the diamond nanoparticles, which enables the oil to retain a thin film of the lubricant even at higher loading conditions (Chu et al. 2010) that is also evident in Fig. 22a, b. Optical microscope images of the wear scars for pure base oil, h-BN oil and h-BN/ND oil are shown in Fig. 24. The wear scar is reduced by 11.82 and $17.58 \%$ in comparison to h-BN oil and base oil, respectively.

Based on the above discussions, the improvement in friction with the use of ND may be attributed to the rolling action, due to which the COF reduces by a considerable amount. However, the improvement in wear is due to the polishing effect caused by hard diamond nanoparticles. The rolling of hard diamond nanoparticles smoothens the sharp asperities, which leads to the decrease in wear volume. The action of diamond nanoparticles can also be seen in Fig. 7a, wherein fine grooves indicating the rolling of these nanoparticles are visible. The wear in this case is mainly due to the ploughing action of hard ND particles, which indicates that abrasion is the dominant wear mechanism.

The studies carried out reveal that the addition of diamond nanoparticles provides better synergism with $\mathrm{CuO}$ and h-BN nanoparticles. Apart from improving the frictional characteristics, it also serves as a potential candidate under extreme pressure conditions. 


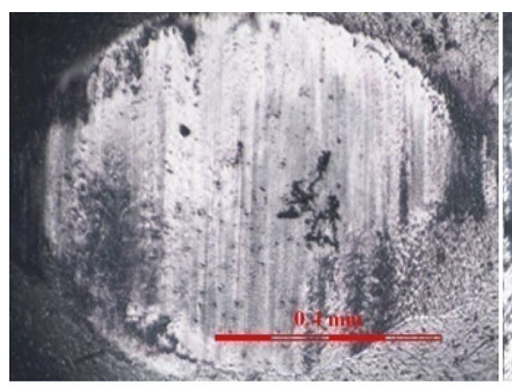

(a)

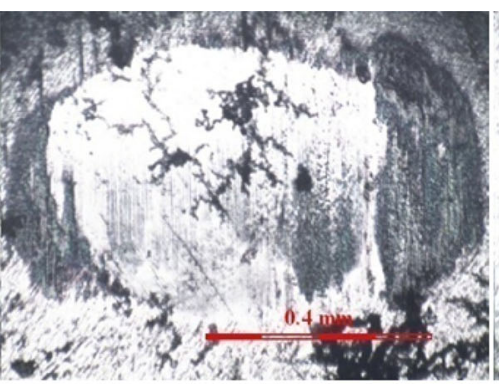

(b)

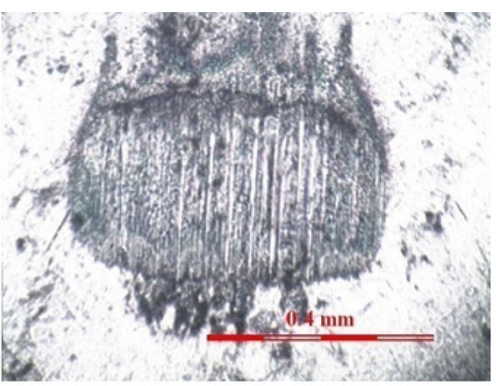

(c)

Fig. 22 Optical microscope images of steel balls. a PAO oil, b $\mathrm{CuO}$ oil, $\mathbf{c} \mathrm{CuO} / \mathrm{ND}$ oil

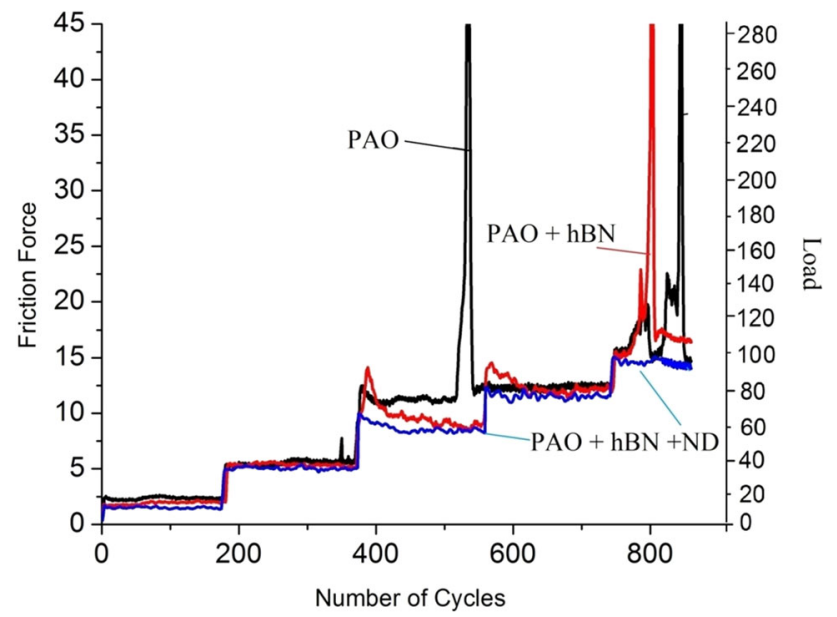

Fig. 23 Frictional force characteristics at different loads increased in a stepwise manner from 20 to $100 \mathrm{~N}$

\section{Conclusion}

Experiments were performed to evaluate the lubricating effect of diamond nanoparticles with $\mathrm{CuO}$ and h-BN additives in the PAO base oil. From the investigations performed, the following conclusions can be drawn:

1. The frictional characteristics of the $\mathrm{CuO} / \mathrm{ND}$ oil are much better than the oil containing $\mathrm{CuO}$ and diamond nanoparticles alone. A maximum of $15.45 \%$ decrease in the friction coefficient was observed with the use of $\mathrm{CuO} / \mathrm{ND}$ oil in comparison to the $\mathrm{CuO}$ oil. The wear characteristics also showed a significant improvement in wear properties. A decrease of $67.71 \%$ in wear volume was observed with the use of $\mathrm{CuO} / \mathrm{ND}$ corresponding to a load of $100 \mathrm{~N}$. In the micrographs obtained from SEM, some fine grooves can be observed on the wear track suggesting the rolling action of hard diamond nanoparticles. Although wear in this case is also evident, layer formation is predominant. Moreover, the corners visible on the SEM image (Fig. 7a) confirm the film formation capability of the $\mathrm{CuO}$ nanoparticles.

2. Results obtained for the second case also revealed the better performance of h-BN/ND oils in comparison to the h-BN and ND oil alone. A maximum of 25.45 and $69.3 \%$ decrease in the friction coefficient and wear volume was observed with the use of h-BN/ND oils, when compared with h-BN oil at a load of $100 \mathrm{~N}$. SEM images obtained therein reveal that surface damage because the delamination wear is substantially less. This is due to the polishing effect caused by diamond nanoparticles which leads to the decrease in wear volume.

3. Experiments performed to evaluate the climbing load characteristics of $\mathrm{CuO} / \mathrm{ND}$ and $\mathrm{h}-\mathrm{BN} / \mathrm{ND}$ oil also demonstrated superior properties. The retention of oil

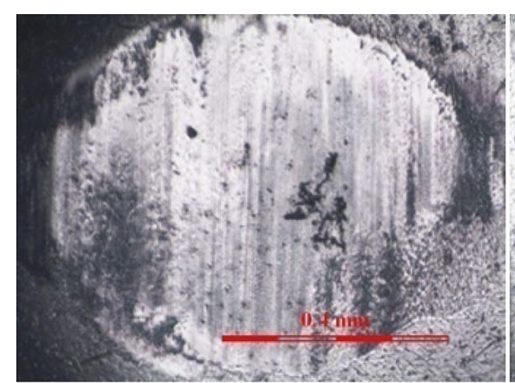

(a)

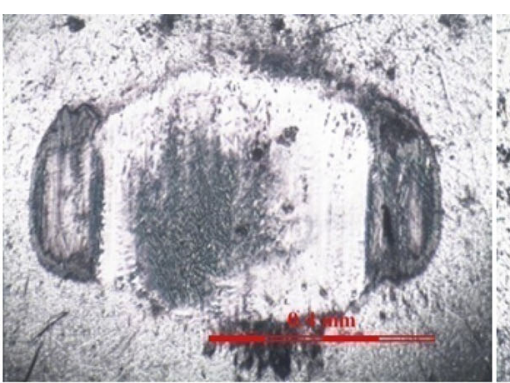

(b)

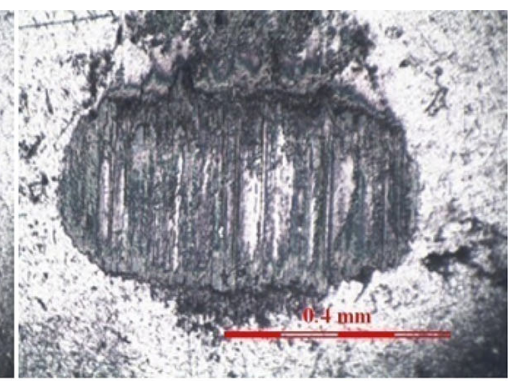

(c)

Fig. 24 Optical microscope images of steel balls. a PAO oil, b h-BN oil, c h-BN/ND oil 
film at high loads and the decrease in the wear confirm the high load-carrying capacities of the diamond nanoparticles.

Therefore, the above results indicate that the film formation capabilities of $\mathrm{CuO}$ and h-BN nanoparticles and the polishing effect of diamond nanoparticles lead to the improvement in wear behavior of different lubricating oils. The investigations performed herein indicate that the nanodiamond, owing to its intrinsic characteristics, can serve as a potential candidate in the field of industrial lubrication.

Open Access This article is distributed under the terms of the Creative Commons Attribution 4.0 International License (http:// creativecommons.org/licenses/by/4.0/), which permits unrestricted use, distribution, and reproduction in any medium, provided you give appropriate credit to the original author(s) and the source, provide a link to the Creative Commons license, and indicate if changes were made.

\section{Appendix}

Minimum film thickness is given by:

$$
\begin{aligned}
h_{\min }= & 7.43 * R \\
& *\left(1-0.85 \mathrm{e}^{-0.31 k}\right)\left(\eta u / E^{*} R\right)^{0.65}\left(L / E^{*} R^{2}\right)^{-0.21},
\end{aligned}
$$

radius of ball $\left(R_{\mathrm{a}}\right)=5 \mathrm{~mm}, \quad$ radius of Flat $\operatorname{disc}\left(R_{\mathrm{b}}\right)=$ Infinite, ellipticity parameter $(k)=1, \quad \operatorname{viscosity}(\eta)=$ 0.014 Pa s, mean velocity $(u)=\frac{u_{\mathrm{a}}+u_{\mathrm{b}}}{2}=0.29 \mathrm{~m} / \mathrm{s}$, Poison's ratio of steel ball $\left(v_{\mathrm{a}}\right)=0.3$, Poison's ratio of steel disk $\left(v_{\mathrm{b}}\right)=0.3, \quad$ elasticity modulus of ball $\left(E_{\mathrm{a}}\right)=210 \mathrm{GPa}$, elasticity modulus of $\operatorname{disk}\left(E_{\mathrm{b}}\right)=200 \mathrm{GPa}, \operatorname{normal} \operatorname{load}(\mathrm{L})=$ $100 \mathrm{~N}, \sigma_{\mathrm{a}}=0.020 \mu \mathrm{m}, \sigma_{b}=0.024 \mu \mathrm{m}$,

$\frac{1}{R}=\frac{1}{R_{\mathrm{a}}}+\frac{1}{R_{\mathrm{b}}}$,

$\frac{1}{E^{*}}=\frac{2}{\frac{1-v_{\mathrm{a}}^{2}}{E_{\mathrm{a}}}+\frac{1-v_{\mathrm{b}}^{2}}{E_{\mathrm{b}}}}$,

$\sigma^{*}=\sqrt{\left(\sigma_{\mathrm{a}}^{2}+\sigma_{\mathrm{b}}^{2}\right)}$,

where

$$
\begin{aligned}
& h_{\min }=7.43 * 5 * 10^{-3} *\left(1-0.85 \mathrm{e}^{-0.31(1)}\right) \\
&\left(\frac{0.014 * 0.29}{225.22 * 10^{9} * 5 * 10^{-3}}\right)^{0.65}\left(\frac{100}{225.22 * 10^{9} * 25 * 10^{-6}}\right)^{-0.21}, \\
& h_{\min }=7.43 * 5 * 10^{-3} *(0.3765) *\left(3.647 * 10^{-8}\right) *(9.945), \\
& h_{\min }=507.311 * 10^{-11} \mathrm{~m}, \\
& h_{\min }=5.073 \mathrm{~nm} .
\end{aligned}
$$

\section{References}

Abdullah MIHC, Abdollah MFB, Tamaldin N, Amiruddin H, Mat Nuri NR (2016) Effect of hexagonal boron nitride nanoparticles as an additive on the extreme pressure properties of engine oil. Ind Lubr Tribol 68(4):441-445

Alves S, Mello V, Faria E, Camargo A (2016) Nanolubricants developed from tiny $\mathrm{CuO}$ nanoparticles. Tribol Int 100:263-271

Battez AH, Gonzalez R, Felgueroso D, Fernández J, del Rocío FM, García M, Penuelas I (2007) Wear prevention behaviour of nanoparticle suspension under extreme pressure conditions. Wear 263(7):1568-1574

Çelik O, Ay N, Göncü Y (2013) Effect of nano hexagonal boron nitride lubricant additives on the friction and wear properties of AISI 4140 steel. Part Sci Technol 31(5):501-506

Chou CC, Lee SH (2010) Tribological behavior of nanodiamonddispersed lubricants on carbon steels and aluminum alloy. Wear 269(11):757-762

Chu HY, Hsu WC, Lin JF (2010) The anti-scuffing performance of diamond nano-particles as an oil additive. Wear 268(7):960-967

Elomaa O, Hakala TJ, Myllymäki V, Oksanen J, Ronkainen H, Singh VK, Koskinen J (2013) Diamond nanoparticles in ethylene glycol lubrication on steel-steel high load contact. Diam Relat Mater 34:89-94

Hamrock BJ, Dowson D (1978) Elastohydrodynamic lubrication of elliptical contracts for materials of low elastic modulus: I. Fully flooded conjunction. J Lubr Technol 100:236-245

Ivanov M, Pavlyshko S, Ivanov D, Petrov I, Shenderova O (2010) Synergistic compositions of colloidal nanodiamond as lubricantadditive. J Vac Sci Technol B Nanotechnol Microelectr Mater Process Meas Phenom 28(4):869-877

Ivanov M, Ivanov D, Pavlyshko S, Petrov I, Vargas A, McGuire G, Shenderova O (2012) Nanodiamond-based nanolubricants. Fuller Nanotub Carbon Nanostruct 20(4-7):606-610

Jatti VS, Singh T (2015) Copper oxide nano-particles as frictionreduction and anti-wear additives in lubricating oil. J Mech Sci Technol 29(2):793-798

Kim HS, Park JW, Park SM, Lee JS, Lee YZ (2013) Tribological characteristics of paraffin liquid with nanodiamond based on the scuffing life and wear amount. Wear 301(1):763-767

Kim ST, Woo JY, Lee YZ (2016) Friction, wear, and scuffing characteristics of marine engine lubricants with nanodiamond particles. Tribol Trans 59(6):1098-1103

Liu G, Li X, Qin B, Xing D, Guo Y, Fan R (2004) Investigation of the mending effect and mechanism of copper nano-particles on a tribologically stressed surface. Tribol Lett 17(4):961-966

Marko M, Kyle J, Branson B, Terrell E (2015) Tribological improvements of dispersed nanodiamond additives in lubricating mineral oil. J Tribol 137(1):011802

Michail IG, Ivanov DM, Petrov I, McGuire G, Shenderova O (2009) Nanodiamonds particles as additives in lubricants. MRS Online Proceedings Library Archive, 1203-J17-16

Mochalin VN, Shenderova O, Ho D, Gogotsi Y (2012) The properties and applications of nanodiamonds. Nat Nanotechnol 7(1):11-23

Mordukhovich G, Qu J, Howe JY, Bair S, Yu B, Luo H, Smolenski DJ, Blau PJ, Bunting BG, Dai S (2013) A low-viscosity ionic liquid demonstrating superior lubricating performance from mixed to boundary lubrication. Wear 301:740-746

Novak C, Kingman D, Stern K, Zou Q, Gara L (2014) Tribological properties of paraffinic oil with nanodiamond particles. Tribol Trans 57(5):831-837 
Nunn N, Mahbooba Z, Ivanov M, Ivanov D, Brenner D, Shenderova O (2015) Tribological properties of polyalphaolefin oil modified with nanocarbon additives. Diam Relat Mater 54:97-102

Padgurskas J, Rukuiza R, Prosyčevas I, Kreivaitis R (2013) Tribological properties of lubricant additives of $\mathrm{Fe}, \mathrm{Cu}$ and $\mathrm{Co}$ nanoparticles. Tribol Int 60:224-232

Pawlak Z, Kaldonski T, Pai R, Bayraktar E, Oloyede A (2009) A comparative study on the tribological behaviour of hexagonal boron nitride (h-BN) as lubricating micro-particles-an additive in porous sliding bearings for a car clutch. Wear 267(5):1198-1202

Peña-Parás L, Taha-Tijerina J, Garza L, Maldonado-Cortés D, Michalczewski R, Lapray $\mathrm{C}$ (2015) Effect of $\mathrm{CuO}$ and $\mathrm{Al}_{2} \mathrm{O}_{3}$ nanoparticle additives on the tribological behavior of fully formulated oils. Wear 332:1256-1261

Peng D, Kang Y, Hwang R, Shyr S, Chang Y (2009a) Tribological properties of diamond and $\mathrm{SiO}_{2}$ nanoparticles added in paraffin. Tribol Int 42(6):911-917
Peng DX, Kang Y, Chen CH, Chen Fu-chun Shu SK (2009b) The tribological behavior of modified diamond nanoparticles in liquid paraffin. Ind Lubr Tribol 61(4):213-219

Reeves CJ, Menezes PL, Lovell MR, Jen TC (2013) The size effect of boron nitride particles on the tribological performance of biolubricants for energy conservation and sustainability. Tribol Lett 51(3):437-452

Shenderova O, Vargas A, Turner S, Ivanov D, Ivanov M (2014) Nanodiamond-based nanolubricants: investigation of friction surfaces. Tribol Trans 57(6):1051-1057

Thottackkad VM, Rajendrakumar P, Prabhakaran Nair K (2014) Experimental studies on the tribological behaviour of engine oil (SAE15W40) with the addition of $\mathrm{CuO}$ nanoparticles. Ind Lubr Tribol 66(2):289-297

Vadiraj A, Manivasagam G, Kamani K, Sreenivasan V (2012) Effect of nano oil additive proportions on friction and wear performance of automotive materials. Tribol Ind 34(1):3-10

Wu Y, Tsui W, Liu T (2007) Experimental analysis of tribological properties of lubricating oils with nanoparticle additives. Wear 262(7):819-825 